\title{
Impact of Fire Attack Utilizing Interior and Exterior Streams on Firefighter Safety and Occupant Survival: Air Entrainment
}

Craig Weinschenk

Keith Stakes

Robin Zevotek

UL Firefighter Safety Research Institute

Columbia, MD 20145

This publication is available free of charge from: https://dx.doi.org/10.54206/102376/GMAX3657

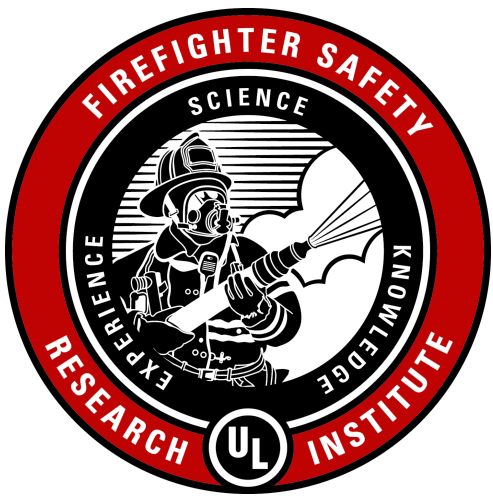





\section{Impact of Fire Attack Utilizing Interior and Exterior Streams on Firefighter Safety and Occupant Survival: Air Entrainment}

Craig Weinschenk

Keith Stakes

Robin Zevotek

UL Firefighter Safety Research Institute

Columbia, MD 21045

December 6, 2017

This publication is available free of charge from:

https://dx.doi.org/10.54206/102376/GMAX3657

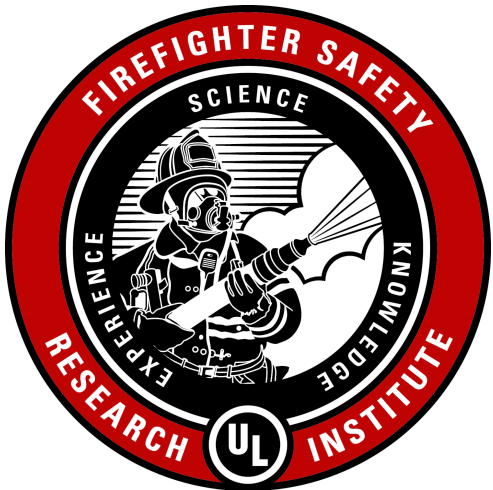

UL Firefighter Safety Research Institute Steve Kerber, Director 
In no event shall UL be responsible to anyone for whatever use or non-use is made of the information contained in this Report and in no event shall UL, its employees, or its agents incur any obligation or liability for damages including, but not limited to, consequential damage arising out of or in connection with the use or inability to use the information contained in this Report. Information conveyed by this Report applies only to the specimens actually involved in these tests. UL has not established a factory Follow-Up Service Program to determine the conformance of subsequently produced material, nor has any provision been made to apply any registered mark of UL to such material. The issuance of this Report in no way implies Listing, Classification or Recognition by UL and does not authorize the use of UL Listing, Classification or Recognition Marks or other reference to UL on or in connection with the product or system. 


\section{Acknowledgments}

This work was funded through a grant from the Department of Homeland Security's Assistance to Firefighters Grant Program under the Fire Prevention and Safety Grants: Research and Development. Without this critical funding and support, this vital fire service research would not be possible.

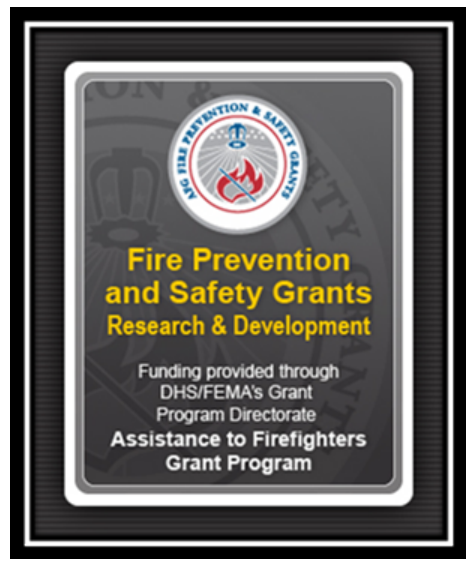


To assist the design and implementation of the experiments for the Fire Attack study, fire service experts from across the world with knowledge in fire suppression and the impact of interior and exterior fire streams were brought together. The individuals below provided direction for the project, assisted in planning the experiments, witnessed the testing, and developed concrete conclusions. Their tireless support and effort make this project relevant to the fire service across the world.

Fire Service Technical Panel

\begin{tabular}{ll}
\hline Name & Fire Department \\
\hline Steve Brisebois & Montreal Fire Department \\
Matt Carrigan & Montgomery County Fire and Rescue Service \\
Tony Carroll & District of Columbia Fire and Emergency Medical Service Department \\
Albert Castillo & Houston Fire Department \\
Chad Christensen & Los Angeles County Fire Department \\
John Chubb & Dublin Fire Brigade \\
Danny Doyle & Pittsburgh Fire Department \\
Aaron Fields & Seattle Fire Department \\
Jason Floyd & Las Cruces Fire Department \\
John Gallagher & Boston Fire Department \\
Chad Green & Anchorage Fire Department \\
Kelly Hanink & Eden Prairie Fire Department \\
Samuel Hittle & Wichita Fire Department \\
Jacob Hoffman & Toledo Fire/Rescue Department \\
Josh Hummel & Howard County Department of Fire and Rescue Services \\
Jerry Knapp & West Haverstraw Fire Department \\
Dennis Legear & Oakland Fire Department \\
Hans Neiling & Zuid Limburg Fire \\
Nick Martin & Columbia Fire Department \\
Ray McCormack & Fire Department of New York \\
John McDonough & New South Wales Fire Department \\
Jordan Mohr & Sedgwick County Fire District 1 \\
Steve Pegram & Goshen Township Fire and EMS \\
\hline & \\
\hline
\end{tabular}

The authors would also like to acknowledge the staff of the Delaware County Emergency Services Training Center for their assistance in conducting the air entrainment experiments. 


\section{Contents}

Contents iv

List of Figures

$\begin{array}{ll}\text { List of Tables } & \text { viii }\end{array}$

$\begin{array}{ll}\text { List of Acronyms } & \text { ix }\end{array}$

1 Background $\quad 2$

1.1 Fire Service Training . . . . . . . . . . . . . . . . . . . . 2

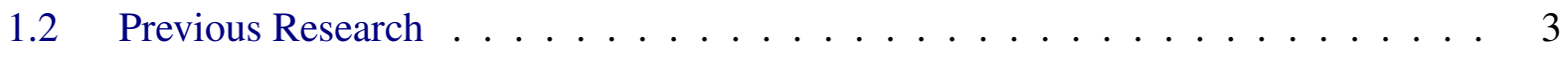

2 Objectives $\quad 5$

3 Experimental Configuration 6

3.1 Test Facility . . . . . . . . . . . . . . . . . . . . . . . . 6

3.2 Equipment Used . . . . . . . . . . . . . . . . . . . . . . . 9

3.3 Instrumentation and Uncertainty . . . . . . . . . . . . . . . . 9

3.4 Measurement Location . . . . . . . . . . . . . . . . . . . . . . 10

3.5 Flow Locations . . . . . . . . . . . . . . . . . . . 13

4 Experiments Conducted $\quad 14$

$4.1 \quad$ Known Source Assessment . . . . . . . . . . . . . . . . . . . . . . 17

4.2 Manufacturer Comparison . . . . . . . . . . . . . . . 18

5 Results $\quad 22$

5.1 Comparison of the Impact of Hose Stream Type . . . . . . . . . . . . . . . . 22

5.2 Comparison of Impact of Nozzle Movement . . . . . . . . . . . . . . . . . . . . . . 24

5.3 Comparison of Impact of Pressure and Flow Rate . . . . . . . . . . . . . . . . 26

6 Discussion $\quad 32$

6.1 Understanding the Basics of Air Entrainment . . . . . . . . . . . . . . 32

6.2 Smooth Bore Streams \& Straight Streams Have Equivalent Air Entrainment . . . 33

6.3 Increasing the Width of a Fog Pattern Increases Air Entrainment . . . . . . . . . . 34

6.4 An Increase in Stream Length Increases Air Entrainment . . . . . . . . . . . . 35

6.4.1 Stream Length and Hydraulic Ventilation . . . . . . . . . . . . . . . . . . . . . 35

6.4.2 Stream Length and Exterior Water Application . . . . . . . . . . . . . . . 36 
6.5 Nozzle Movement Increases Entrainment . . . . . . . . . . . . . . . . . . . 38

6.6 Comparing Entrainment to PPV Fan Exhaust . . . . . . . . . . . . . . . . . 38

6.7 What Did Not Affect Air Entrainment . . . . . . . . . . . . . . 39

7 Future Research Needs $\quad 40$

8 Summary 41

$\begin{array}{ll}\text { References } & 42\end{array}$

$\begin{array}{lll}\text { A Air Entrainment Figures } & 43\end{array}$

B Known Source Experiments $\quad 55$ 


\section{List of Figures}

1.1 Rockland County Fire Training Center Test Setup . . . . . . . . . . . . . 4

3.1 Delaware County, PA Fire Test Structure . . . . . . . . . . . . . . 6

3.2 Delaware County, PA Fire Test Structure First Floor . . . . . . . . . . . . . 7

3.3 Delaware County, PA Fire Test Structure Second Floor ～. . . . . . . . . . . . 8

3.4 Nozzle Prop . . . . . . . . . . . . . . . . . . . . . . . 10

3.5 Nozzle Prop in Use . . . . . . . . . . . . . . . . . . . . . 10

3.6 Measurement Location (Second Floor) . . . . . . . . . . . . . . . . 11

3.7 Air Entrainment Flowpath, Interior Experiments . . . . . . . . . . . . . . 12

3.8 Air Entrainment Flowpath, Exterior Experiments . . . . . . . . . . . . . . . 12

3.9 First Floor Setup - Total Entrainment Interior Tests . . . . . . . . . . . . . . . 13

3.10 First Floor Setup - Total Entrainment Exterior Tests . . . . . . . . . . . . . 13

4.1 Time History of Entrainment Experiment . . . . . . . . . . . . . . . . . . . . . 14

4.2 Average Flow Rate Comparison . . . . . . . . . . . . . . . . . . . . 15

4.3 Comparison of Known Source to Measured CFM with Single Door Exhaust . . 17

4.4 Comparison of Known Source to Measured CFM with Double Door Exhaust . . . 18

4.5 Average Air Entrainment Varying Manufacturer with Combination Nozzles . . . . 20

4.6 Average Air Entrainment Varying Manufacturer with Smooth Bore Nozzles . . . . 21

5.1 Air Entrainment Comparison of Hose Stream Type Fixed Pattern . . . . . . . . . 22

5.2 Air Entrainment Comparison of Hose Stream Type 'O' Pattern . . . . . . . . . . . 23

5.3 Air Entrainment Comparison of Fixed Versus Moving Patterns . . . . . . . . . . . 24

5.4 Typical Nozzle Patterns . . . . . . . . . . . . . . . . . . . 25

5.5 Air Entrainment Comparison of Movement Patterns . . . . . . . . . . . . . 25

5.6 Air Entrainment Comparison of 'O' Pattern Versus 'Spray and Pray' . . . . . . . 26

5.7 Air Entrainment Comparison of Pattern Rotation Rate . . . . . . . . . . . . 27

5.8 Air Entrainment Comparison of Pressure and Flow Rate for Interior Combination

Nozzle from $13 / 4$ in Line . . . . . . . . . . . . . . . . . . . . . . . 27

5.9 Air Entrainment Comparison of Pressure and Flow Rate for Interior Smooth Bore Nozzle from $13 / 4$ in Line . . . . . . . . . . . . . . . . . . . . . 28

5.10 Air Entrainment Comparison of Pressure and Flow Rate for Interior Combination Nozzle from $21 / 2$ in Line . . . . . . . . . . . . . . . . . . . . . . 28

5.11 Air Entrainment Comparison of Exterior Smooth Bore Nozzle from 2 1/2 in Line . 29

5.12 Air Entrainment Comparison of Interior Smooth Bore Nozzle from $13 / 4$ in Line to $21 / 2$ in Line . . . . . . . . . . . . . . . . . . . . . . . 29 
5.13 Air Entrainment Comparison of Interior Smooth Bore Nozzle from $13 / 4$ in Line to $21 / 2$ in. Line . . . . . . . . . . . . . . . . . . 30

5.14 Air Entrainment Comparison of Exterior Smooth Bore Nozzle from $13 / 4$ in Line to $21 / 2$ in Line . . . . . . . . . . . . . . . . . . . . . 31

6.1 Air Flow Around a Droplet $\ldots \ldots \ldots 32$

6.2 Hydraulic ventilation . . . . . . . . . . . . . . . . . . . 32

6.3 Straight Stream vs. Smooth Bore Stream Across Manufacturers . . . . . . . . . 33

6.4 Straight Stream vs. Smooth Bore Stream Across Manufacturers - 'O' Pattern . . . 34

6.5 Straight Stream vs. Narrow Fog vs. Wide Fog - $3 \mathrm{ft}$ from Opening . . . . . . . . . 35

6.6 Effect of Stream Length on Entrainment - Hydraulic Ventilation . . . . . . . . . 36

6.7 Effect of Stream Length on Entrainment - Exterior Water Application . . . . . . . 37

6.8 Distance From the Opening has an Impact on Air Entrainment . . . . . . . . . . 37

6.9 Single Story Structure Exhaust - PPV . . . . . . . . . . . . . . . . . . . . . . 39

A.1 Air Entrainment Results Varying Distances from the Ventilation Opening . . . . 43

A.2 Air Entrainment Results Varying Ventilation Opening Occlusion . . . . . . . . . . 43

A.3 Manufacturer I Air Entrainment from Combination Nozzle Varying Pressure and Flowrate . . . . . . . . . . . . . . . . . . . . . . 44

A.4 Manufacturer I Air Entrainment from Smooth Bore Nozzle Varying Pressure and Flowrate . . . . . . . . . . . . . . . . . . . . 4 45

A.5 Manufacturer II Air Entrainment from Combination Nozzle Varying Pressure and Flowrate . . . . . . . . . . . . . . . . . . 46

A.6 Manufacturer II Air Entrainment from Smooth Bore Nozzle Varying Pressure and Flowrate . . . . . . . . . . . . . . . . . . 47

A.7 Manufacturer III Air Entrainment from Combination Nozzle Varying Pressure and Flowrate . . . . . . . . . . . . . . . . . . . . 48

A.8 Manufacturer III Air Entrainment from Smooth Bore Nozzle Varying Pressure and Flowrate . . . . . . . . . . . . . . . . . . . . . . . . 49

A.9 Air Entrainment for 'O' Pattern versus 'Spray and Pray' . . . . . . . . . . . . 50

A.10 Air Entrainment for 2 1/2 in Hoseline with Combination Nozzle from Interior . . 51

A.11 Air Entrainment for 2 1/2 in Hoseline with Smooth Bore Nozzle from Interior . . 52

A.12 Air Entrainment for 2 1/2 in Hoseline with Smooth Bore Nozzle from Exterior . . 53

A.13 Air Entrainment for $13 / 4$ in Hoseline with All Nozzle Patterns from Interior . . . 54

B.1 Air Entrainment with Known Source: Blower Door Test with Single Door Exhaust 55

B.2 Air Entrainment with Known Source: Blower Door Test with Double Door Exhaust 56 


\section{List of Tables}

$3.1 \quad$ Nozzles Used In Testing . . . . . . . . . . . . . . . . . . . . . . . . . 9

$4.1 \quad$ Air Entrainment Experiments . . . . . . . . . . . . . . . . . . 16

4.2 Manufacturer Comparison Experiments . . . . . . . . . . . . . . . . . . . 19 


\section{List of Acronyms}

$\begin{array}{ll}\text { AFG } & \text { Assistance to Firefighters Grant program } \\ \text { CFM } & \text { Cubic Feet per Minute } \\ \text { DHS } & \text { U.S Department of Homeland Security } \\ \text { FEMA } & \text { Federal Emergency Management Agency } \\ \text { NIST } & \text { National Institute of Standards and Technology } \\ \text { NF } & \text { Narrow Fog } \\ \text { SB } & \text { Smooth Bore } \\ \text { SS } & \text { Straight Stream } \\ \text { UL FSRI } & \text { UL Firefighter Safety Research Institute } \\ \text { USFA } & \text { United States Fire Administration }\end{array}$




\section{Abstract}

As research continues into how fire department interventions affect fire dynamics in the modern fire environment, questions continue to arise on the impact and implications of interior versus exterior fire attack on both firefighter safety and occupant survivability. Previous research into various types of fire ground ventilation, flow paths, and exterior fire streams has provided the fire service with an increased understanding of fire dynamics. However, in some instances, the information from the studies did not support current, experience-based practices. This gap between the research to date and the fire ground suppression experience has driven the need for further study.

This study will build upon the fire research conducted to date by analyzing how firefighting tactics, specifically different fire suppression tools and tactics, affect the thermal exposure and survivability of both firefighters and building occupants and affect fire behavior in structures. The purpose of this study is to improve firefighter safety, fire ground tactics, and the knowledge of fire dynamics by providing the fire service with scientific information, developed from water flow and full-scale fire testing, in representative single-family homes. The project will be comprised of 3 parts:

This study will build and expand upon the fire research conducted to date by analyzing how firefighting tactics, specifically suppression methods, affect the thermal exposure and survivability of both firefighters and building occupants in addition to impacting fire behavior in structures. The purpose of this study is to improve firefighter safety, fireground tactics, and the knowledge of fire dynamics by providing the fire service with credible scientific information, developed from both water flow and full-scale fire testing, in representative single family homes. The project is comprised of 3 parts:

- Part I: Water Distribution

- Part II: Air Entrainment

- Part III: Full-Scale Residential Fire Experiments

This report details the results and analysis from the air entrainment testing. These tests were conducted without the presence of fire to gain a fundamental understanding of how hose streams entrain air. Each set of experiments was intended to add to the understanding of air entrainment and pressure from fire service hose streams by evaluating the differences caused by various application methods, hose stream types, nozzle movements, pressures/flow rates, manufacturers, and ventilation configurations. 


\section{Background}

Firefighter research has highlighted the need to apply water to the fire as quickly as possible from the safest and most tactically-efficient location available [1-3]. This includes the option to apply water to the fire from the exterior of the structure, a tactic that was long said to be dangerous for civilian occupants and firefighters alike. As the possibility of utilizing an exterior attack as an offensive operation gained exposure, a knowledge gap was highlighted within the firefighting community which increased interest in better understanding the impact of water applied as part of either an interior or exterior attack. The many variables in fire attack have a direct impact on victim survivability, firefighter safety, and the overall effectiveness of the operation including, the time required to get water on the fire; hose stream type, placement, and movement; air entrainment; steam development; hot gas cooling and contraction; ventilation; and the position of flow paths within the structure. Additionally, firefighters have the ability to make tactical choices on the fire ground which directly affect not only the outcome of the operation but the safety of both civilians and firefighters alike. These choices range from "big picture" decisions on strategies and tactics (i.e. methods of fire attack) down to smaller-scale decisions regarding the tools utilized for suppression operations (i.e. hose lines, nozzles, and hose streams). It is critical that firefighters understand how their tools can impact the fire behavior and air flows within a structure and what impact this may have on suppression operations as well as any implications to victim survivability or firefighter safety.

\subsection{Fire Service Training}

Current firefighter training manuals fail to highlight the importance of air entrainment from hose streams on both fire behavior and air flows within a structure. As little research has been done to date, the effects of changing nozzles, hose stream types, and nozzle movements is unknown and speculative at best. During training, firefighters are instructed on the construction, mechanics, and operation of different nozzle types. Additionally, the various types of hose streams and the associated risks and benefits are discussed. However, there is no mention of the ability of different nozzles and hose streams to affect the air flows within a structure based on a given tactic and hand line set-up. This has been a key component missing from firefighter training for decades. It is imperative that the firefighter operating the nozzle understand how their tools impact their working environment.

Nearly every firefighter training manual introduces the concept of hydraulic ventilation in which the nozzle firefighter is several feet back from an opening within the structure and directs a fog stream from the interior to the exterior of the compartment [4,5]. The fog stream is intended to fill the majority of the ventilation opening. It is discussed that the stream passing through the opening will draw smoke from the compartment and/or remaining parts of the structure to provide ventilation post fire knockdown. The concept of hydraulic ventilation implies that a hose stream entrains 
air; however, there is no direct mention that the smoke is being entrained into the hose stream. The lack of inclusion of air entrainment in training manuals leaves firefighters with only a partial understanding of why hydraulic ventilation occurs and omits a critical piece understanding the operations and implications of various nozzles and hose stream types. Additionally, several firefighter training manuals mention that if a smooth bore nozzle is used during suppression operations, hydraulic ventilation can still be achieved. It is stated that a smooth bore nozzle can be cracked to half or partial bale to create a coarse or broken stream, filling the ventilation opening, and drawing smoke with it. Some manuals even go so far as to say that smooth bore nozzles should be rotated within the window opening to increase the amount of smoke removed from the compartment [5], implying that increasing nozzle movement increases the amount of air entrained. Firefighter training manuals need to include the concept of air entrainment in hose streams into the discussion of nozzles, hose stream types, and nozzle movements. The implication of air entrainment should not just lie in a discussion of hydraulic ventilation within a ventilation chapter.

\subsection{Previous Research}

In 2002, a series of air entrainment experiments was conducted at the Rockland County (NY) Fire Training Center with the goal of quantifying the amount of air moved by various nozzles [6]. Fire service professionals Jerry Knapp, Tim Pillsworth, and Sean White recognized the need for the nozzle firefighter to understand what happens to the fire conditions in a building as a result of their water application. It was noted that the effects of the nozzle, stream pattern, and associated air movement often go unseen as the smoke-filled environment limits visibility. This study was the first of its kind in which the nozzles were flowed in typical fireground methods and the air moved was captured. Ventilation was provided both behind and in front of the nozzle operator. The test fixture was a modular shipping container, divided by a draft wall in which an airflow-measuring device was placed, as shown in Figure 1.1. The device measured velocity and volumetric flow and was repurposed from HVAC installation and duct balancing. Tests were performed looking at nozzle type, hose stream type, nozzle movements, and distance from the ventilation opening. This work led to some of the first quantified conclusions regarding air entrainment in hose streams. The tests showed that smooth bore nozzles entrained the least amount of air, followed by straight streams and fog streams from a combination nozzle. It was also seen that increasing the distance from the nozzle to the ventilation opening increased the entrainment within the hose stream. Rotating the nozzle in a clockwise fashion increased the entrainment as well [6-8]. Limitations to this early work include measurements that were limited to approximately $2000 \mathrm{ft}^{3} / \mathrm{min}$ and measurement losses due to the mechanical measurement device. The upper measurement limit for air entrainment also prevented the testing of larger flow rate common to $21 / 2$ in hoselines.

In 2005, engineers with the National Institute of Standards and Technology (NIST) conducted research on the impact of hose streams on air flows inside a structure through seven experimental series at the Delaware County Emergency Services Training Center in Sharon Hill, PA [9]. The experiments performed which examined various hose stream types, including a straight stream, a narrow fog stream, and a wide fog stream from a combination nozzle as well as a solid stream from a smooth bore nozzle. The nozzle was placed at the threshold of the inlet vent, flowing water into 


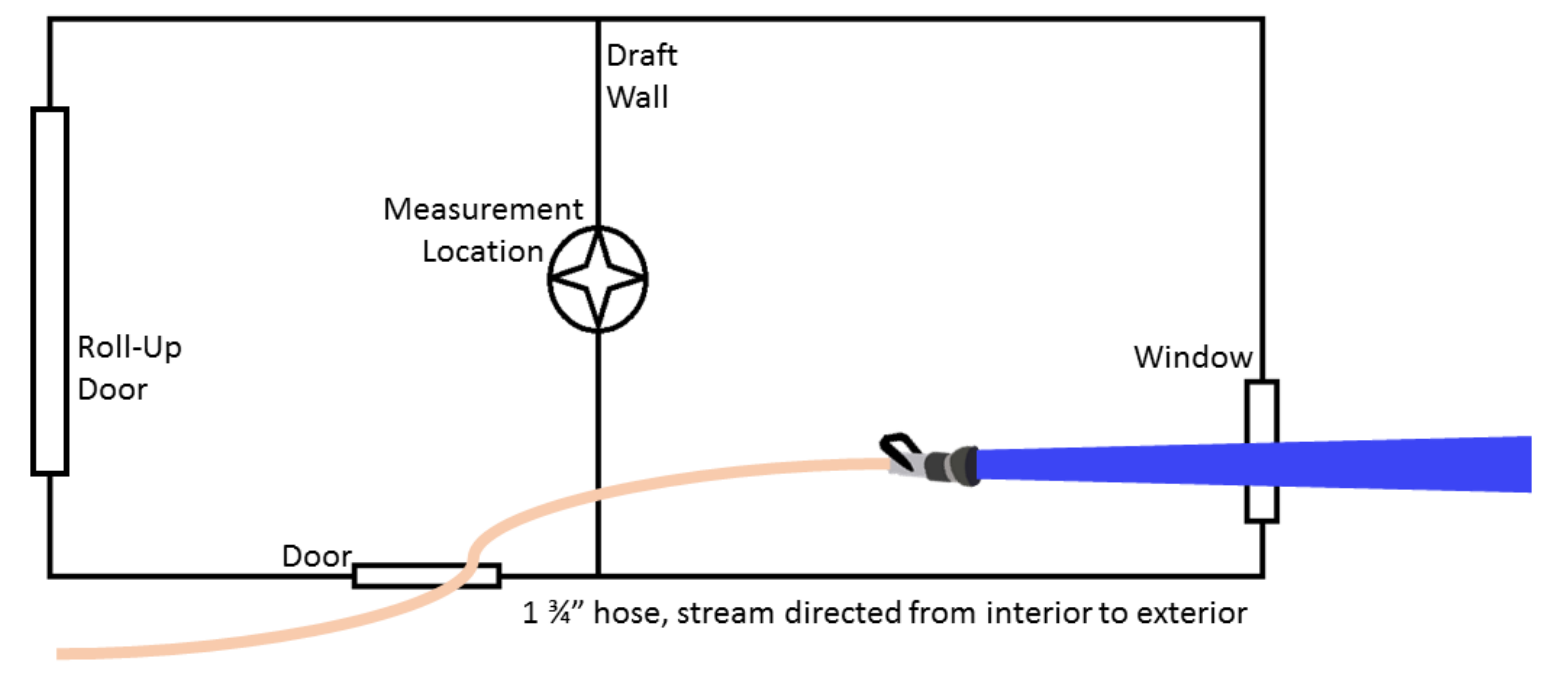

Figure 1.1: Rockland County Fire Training Center Test Setup

the structure for all the experiments. Nozzle movements included fixed, sweeping, and rotational patterns. The gas velocity was measured in the flow path through the use of bi-directional probes to collect both velocity and air flow rate data. It was determined that both the type of hose stream and application pattern are critical factors when analyzing the impact to air flows inside a structure. Similar to the results of the Rockland County experiments, it was concluded that a solid stream entrains less air than a straight stream nozzle which entrains less air than a fog pattern of varying widths. Additionally, it was found that moving and/or rotating the nozzle entrains more air than a fixed stream, as seen before. The work conducted by NIST built upon the earlier work by Knapp et al. but was also limited by examining only combination nozzles; one $13 / 4$ in hoselines at a fixed pressure and flow rate; and only exterior flow conditions.

The fire attack study is intended to close the knowledge gap and provide both context and substantiation to fire suppression methods, tools, and tactics that have been utilized for decades. The results from this study will provide the fire service with scientific knowledge on the impact of both interior and exterior fire attack on victim survivability and firefighter safety. Part II of the study, examining air entrainment in hose streams, is the second of two series of experiments looking at the mechanics of hose streams without the presence of fire. The is intended to provide the fire service with a knowledge base into how nozzles distribute water via different hose stream types, nozzle movements, and attack locations in addition to quantifying how nozzles entrain and move air throughout a structure. By developing data in realistic structures utilizing modern fuel sources and fire scenarios, important inferences may be developed relative to different nozzles, hose stream types, techniques, and the overall use of water for fire suppression operations. 


\section{Objectives}

The purpose of this part to the overall study was to provide the fire service with scientific knowledge on the impact of air entrainment in hose streams during interior and exterior fire attack on firefighter safety and the survivability of trapped occupants. This was accomplished with the completion of the following objectives:

- Improve firefighter safety by increasing knowledge of air entrainment by hose streams.

- Quantify air entrainment of typical fire service nozzles.

- Develop knowledge of how manufacturer, hose stream type, pressure, flow rate, and nozzle movement effect air entrainment.

- Develop and disseminate knowledge of how tactical choices such as ventilation, attack method, and nozzle movement effect air entrainment. 


\section{Experimental Configuration}

\subsection{Test Facility}

The air entrainment testing was conducted at the Delaware County Emergency Services Training Center in Sharon Hill, PA. A two-story concrete structure was built on a concrete slab as shown in Fig. 3.1. It was designed to simulate a representative residential structure.

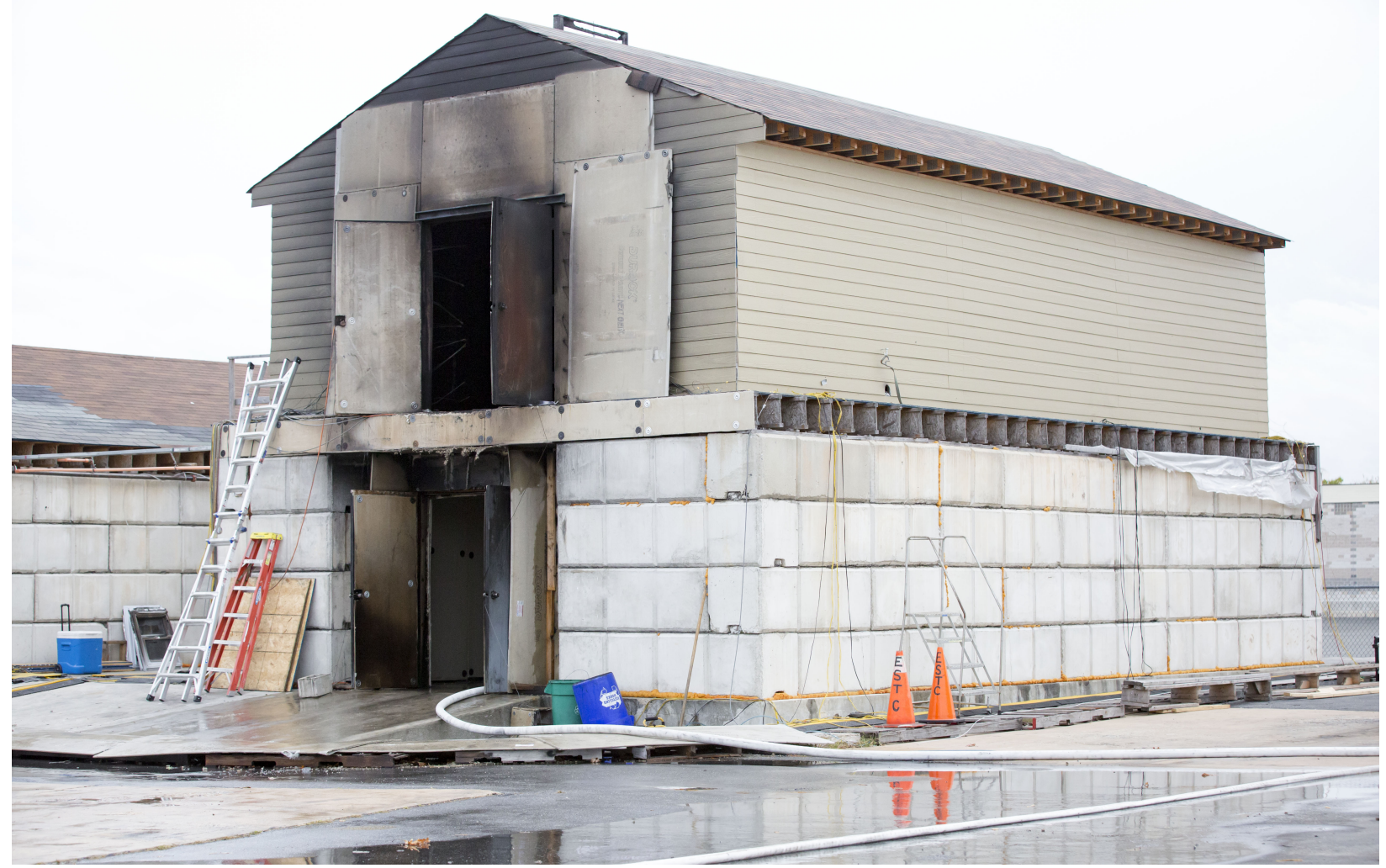

Figure 3.1: Delaware County, PA Fire Test Structure

The outer walls of the first floor of the structure were composed of interlocking concrete blocks $2 \mathrm{ft}$ wide, $2 \mathrm{ft}$ high, and $4 \mathrm{ft}$ long. The interior dimensions of the structure were $20 \mathrm{ft}$ wide, $36 \mathrm{ft}$ long, and $8 \mathrm{ft}$ high. The joints and gaps between the blocks were filled with high temperature insulation. The interior walls of the first floor were framed with steel studs set to 16 in centers and track and were lined with $0.5 \mathrm{in}$. thick cement board. The walls were composed of 0.6 in Type X gypsum board. Additionally, the ceiling was composed of two layers of $0.5 \mathrm{in}$. thick cement board. The first-floor ceiling support of the structure was composed of wood truss joist I-beams (TJIs) with a 11.75 in depth. Each TJI was composed of laminated veneer lumber flanges with a cross section of 1.13 in $x 1.75$ in and an 0.43 in thick oriented strand board web. Tongue and groove oriented 
strand board of 0.72 in thickness was screwed to the top of the TJIs.

A stairwell was built to connect the two floors of the structure. The stairs had a 7.25 in rise and 7.5 in run and started $5.25 \mathrm{ft}$ off the south wall with a width of $14 \mathrm{ft}$ off the east wall. The second story walls were wood-framed with 2 in by 4 in studs. The studs were set to 16 in centers. The interior walls were protected by 0.63 in fire-rated gypsum board, 0.63 in Durock board, and a second layer of 0.63 in fire-rated gypsum board. The exterior walls were protected with 0.31 in oriented strand board and 0.31 in fiber cement lap siding. Dimensioned drawings of the first and second floor are shown in Figures 3.2 and 3.3 respectively.

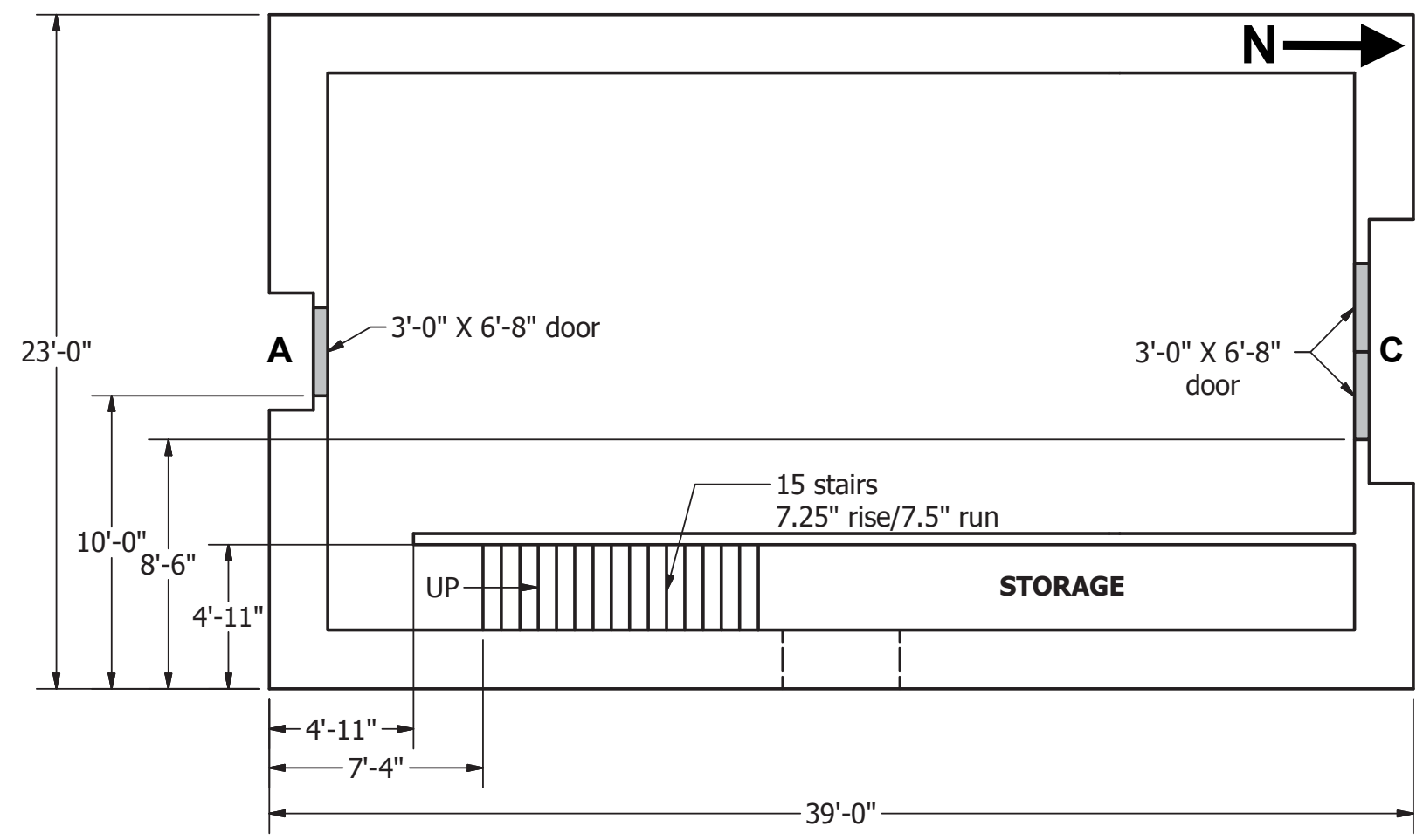

Figure 3.2: Delaware County, PA Fire Test Structure First Floor

The exterior doorways of each structure featured steel doors that were opened or closed at certain instances during tests to change the ventilation configuration within the structure. All other doorways in the structures did not contain a door. If it was determined that these doors needed to be closed during a test, a sheet of either gypsum board or oriented strand board was used to cover the opening and remained as such until the conclusion of the given test. 


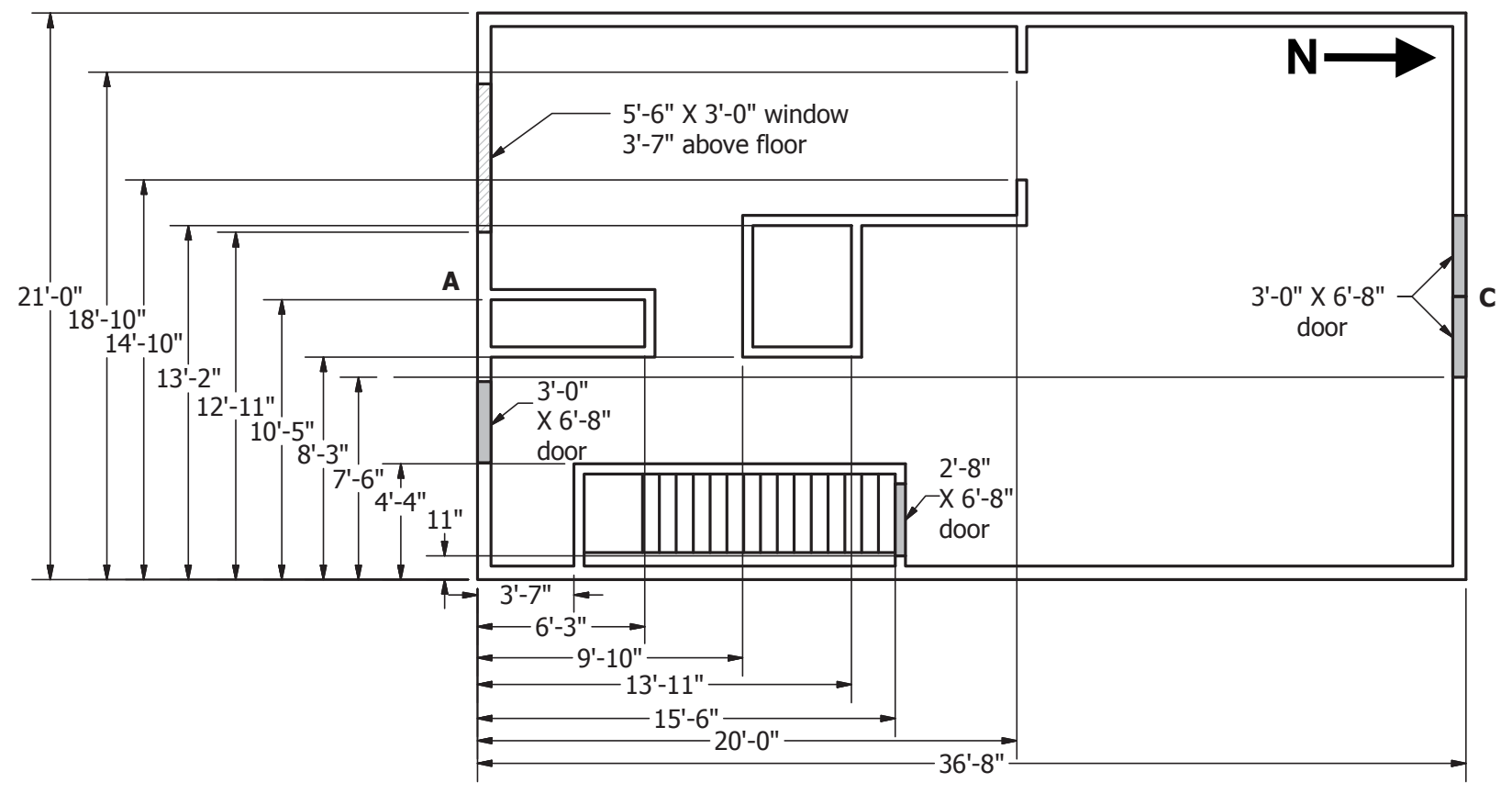

Figure 3.3: Delaware County, PA Fire Test Structure Second Floor 


\subsection{Equipment Used}

To ensure the data collected and associated results were applicable to the majority of the fire service, a list of representative nozzles, specified flow rates/pressures, and nozzle movement techniques was created. The variables, which were used during the air entrainment experiments are included in the Table 3.1.

Table 3.1: Nozzles Used In Testing

\begin{tabular}{llccc}
\hline Line Size & Nozzle Type & Tip (in) & Nozzle Pressure (psi) & Approximate Flow Rate (gpm) \\
\hline $13 / 4$ in. & Smooth Bore & 1 & 50 & 210 \\
& Smooth Bore & $15 / 16$ & 50 & 180 \\
& Smooth Bore & $7 / 8$ & 50 & 150 \\
& Combination & & 50 & 150 \\
& Combination & 75 & 150 \\
& Combination & 100 & 100 \\
& Combination & 100 & 150 \\
\hline $21 / 2$ in. & Smooth Bore & $11 / 8$ & 50 & 260 \\
& Smooth Bore $11 / 4$ & 50 & 320 \\
& Combination & 50 & 250 \\
& Combination & 75 & 250 \\
& Combination & 100 & 250 \\
\hline
\end{tabular}

These experiments involved the repetition of nozzle movements and patterns; therefore, to minimize nozzle operator fatigue and improve repeatability a nozzle prop was constructed. The prop was used as the 'backup' firefighter by supporting the hoseline and minimizing nozzle reaction forces on the operator. Figure 3.4 shows a dimensioned drawing and the constructed prop. The horizontal base and vertical member were constructed of 4 in by 4 in dimensioned lumber while the angled supports were constructed of 2 in by 6 in dimensioned lumber.

The hose was affixed to the prop with ' $U$ ' bolts and locking nuts to ensure the hose did not move during an experiment. The prop supported both 1.5 in and 2.5 in hoselines. To ensure the experiments were consistent (independent of variance of nozzle position on the prop), the distance from the nozzle to the ventilation opening was measured from the tip of the nozzle, and not the base of the prop. Figure 3.5 shows the setup for a fixed nozzle pattern with a smooth bore nozzle.

\subsection{Instrumentation and Uncertainty}

Gas velocity, a measure of air entrainment by hose streams, was obtained through the use of an array of bi-directional probes. Bi-directional probes were connected to pressure transducers to evaluate the change in pressure associated with the gas flow. The differential pressure transducer 

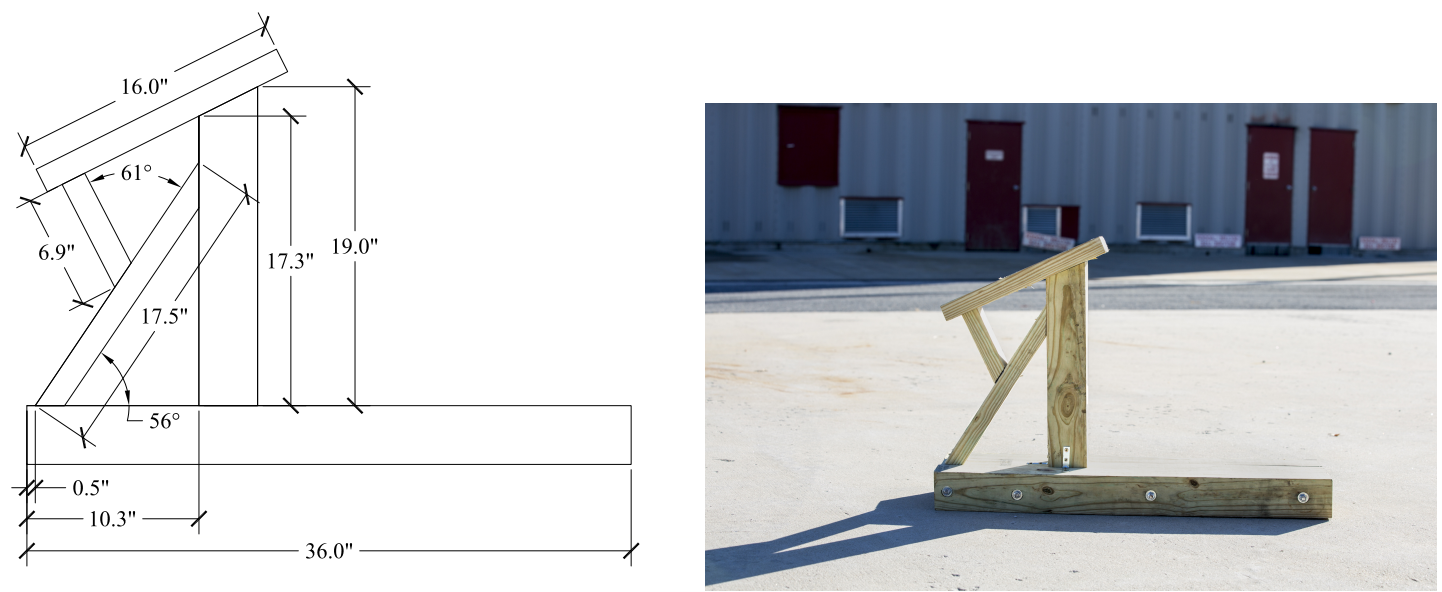

Figure 3.4: Dimensioned drawing of the nozzle prop (left) and constructed prop (right).

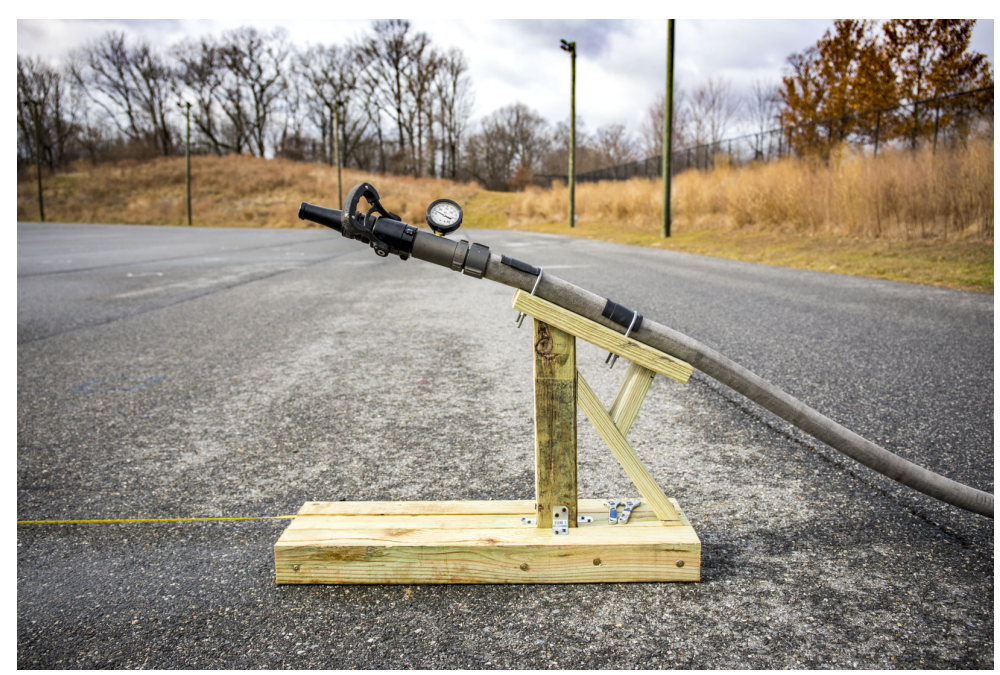

Figure 3.5: Nozzle prop in use for a fixed pattern flow.

was a Setra Model 264 with a range of +/- 0.5 in. WC (+/- $124.5 \mathrm{~Pa}$.). The uncertainty given by the manufacturer is $1 \%$ or $1.2 \mathrm{~Pa}$.

A gas velocity measurement study examining the doorway flow of pre-flashover compartment fires yielded expanded uncertainty measurements ranging from \pm 0.14 to \pm 0.22 for bi-directional probes of similar design [10]. The total expanded uncertainty for gas velocity in these experiments is estimated to be $\pm 18 \%$.

\subsection{Measurement Location}

There were several challenges associated with measuring air entrainment from hose streams. The first challenge existed because the experiments were conducted outside, therefore considering wind 
was critical. Additionally, the instrumentation used in data collection is best in a dry environment to maintain the smallest level of uncertainty and remain operational. To address these challenges, the measurement location was set at the doorway at the top of the stairwell. Figure 3.6 shows the position of the the bi-direction probe array on the second floor.

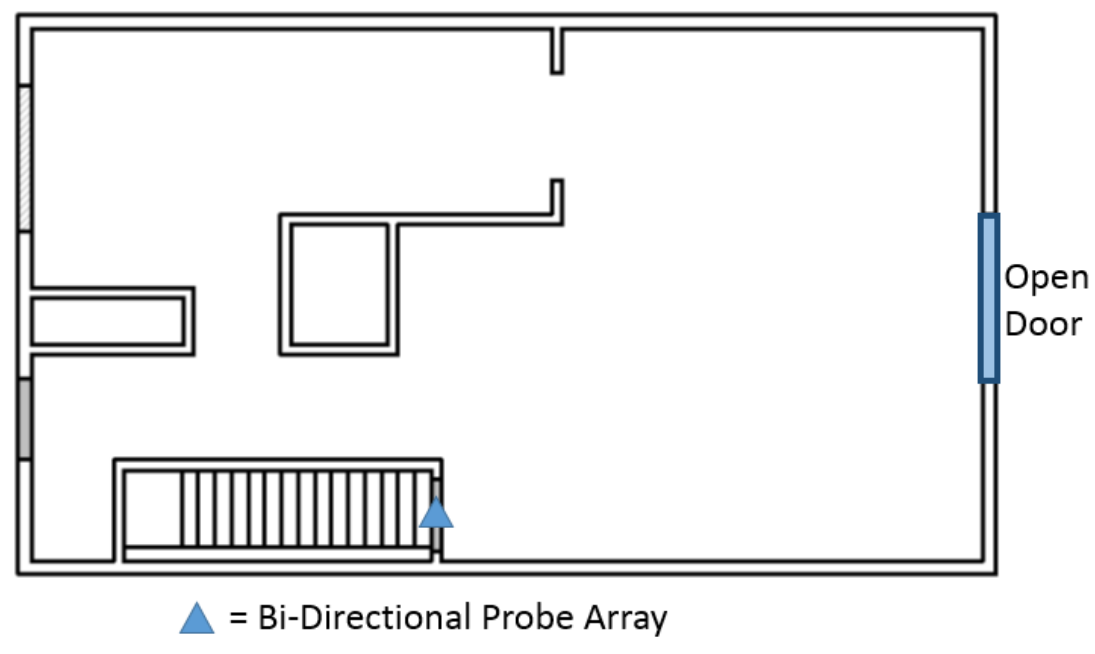

Figure 3.6: Measurement Location (Second Floor)

Figures 3.7 and 3.8 show the experimental configuration for the interior flow tests and exterior flow tests, respectively. The arrows indicate the flow direction based on the hose stream being the source of the flow through air entrainment.

The measurement location was placed at the top of the stairs, within the flow path of both test configurations. This location kept the instrumentation dry and out of the reach of a hose stream. While this location did not guarantee isolation from wind effects due to open vents, this represented the best location to minimize those effects. 


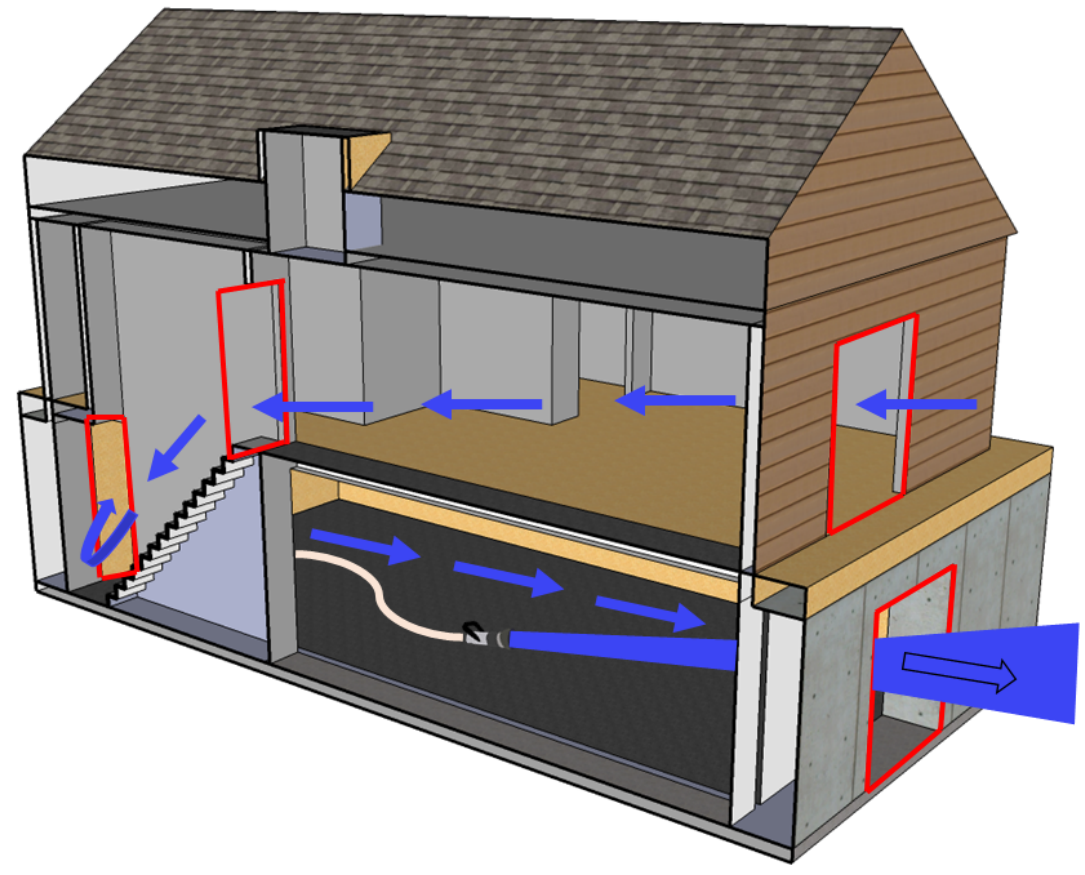

Figure 3.7: Air Entrainment Flowpath, Interior Experiments

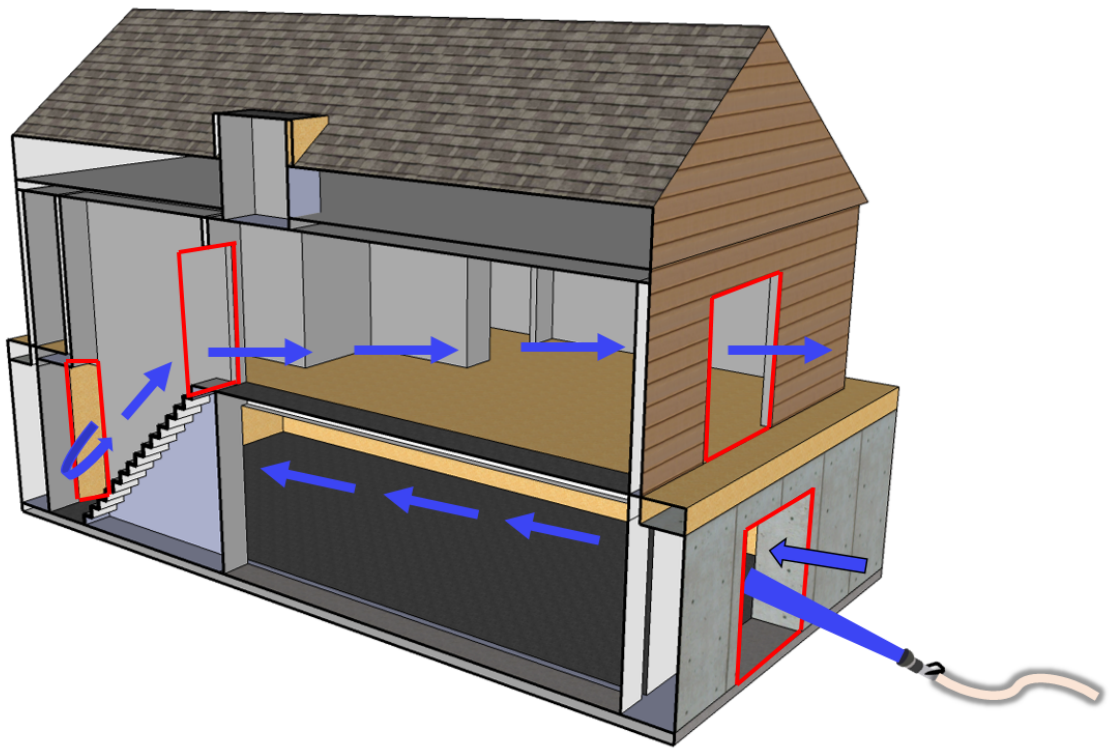

Figure 3.8: Air Entrainment Flowpath, Exterior Experiments 


\subsection{Flow Locations}

For the base configuration of the experimental facility (Figures 3.2 and 3.3), there were two main locations where the hoses were placed to flow water: interior and exterior. For an interior test, the nozzle was set to be $12 \mathrm{ft}$ from the doorway on the first floor of the structure and water flowed from that position through the open vent, out of the structure (Figure 3.9). For the exterior tests, the nozzle was again set $12 \mathrm{ft}$ from the first-floor doorway but water flowed from the exterior of structure through the vent into the first floor of the structure (Figure 3.10). This had the global effect of either pulling air past the measurement array on the second floor or pushing air past the measurement array for the interior and exterior locations respectively.

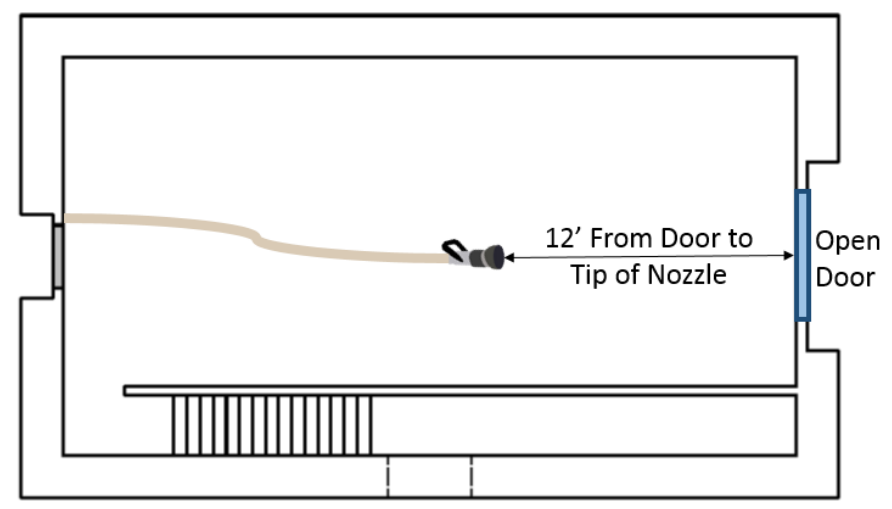

Figure 3.9: First Floor Setup - Total Entrainment Interior Tests

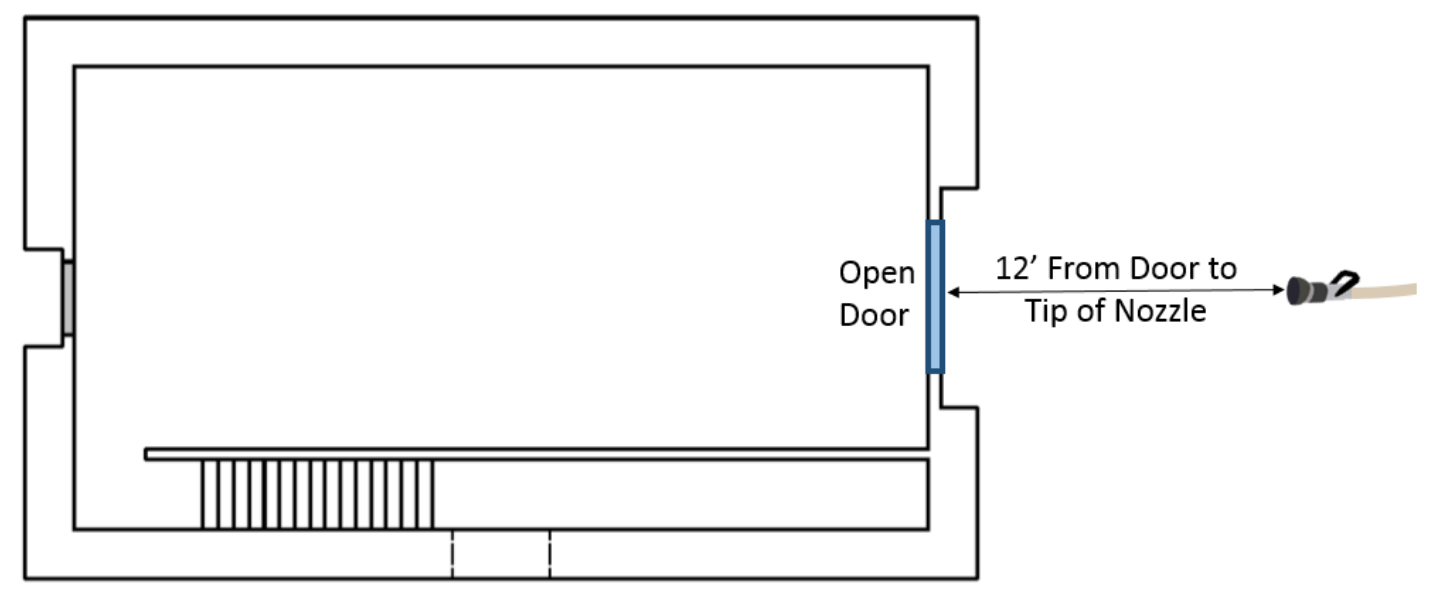

Figure 3.10: First Floor Setup - Total Entrainment Exterior Tests 


\section{Experiments Conducted}

Experiments were completed to determine how air entrainment from hose streams was affected by varying several parameters. In each experimental configuration, water flowed for approximately 60 s. An average velocity was calculated at the measurement location (Section 3.4) using the bidirectional probes and the average velocity was multiplied by the measurement area to calculate a volumetric flow rate in cubic feet per minute (CFM). To compare different configurations, an average flow rate was calculated over the duration for each specific configuration. Figure 4.1 shows the entrained air in volumetric flow as a function of time (dashed line) and the time-averaged flow rate between 'events' (solid line). The time-averaged value was calculated between each event call-out and the value is tied to the event call-out on the left side of the interval. During each test, approximately $60 \mathrm{~s}$ of background data was taken so that the ambient conditions could be isolated from experimental data. After ambient fluctuations were accounted for, the average volumetric flow during the background event was approximately 0 CFM. When the straight stream flow was started in Figure 4.1, the average CFM during that event jumped to approximately 1700 CFM. Note that while the transient (dashed) data shows fluctuations typical of velocity data, the magnitudes of the fluctuations did not prevent distinct events from being distinguishable.

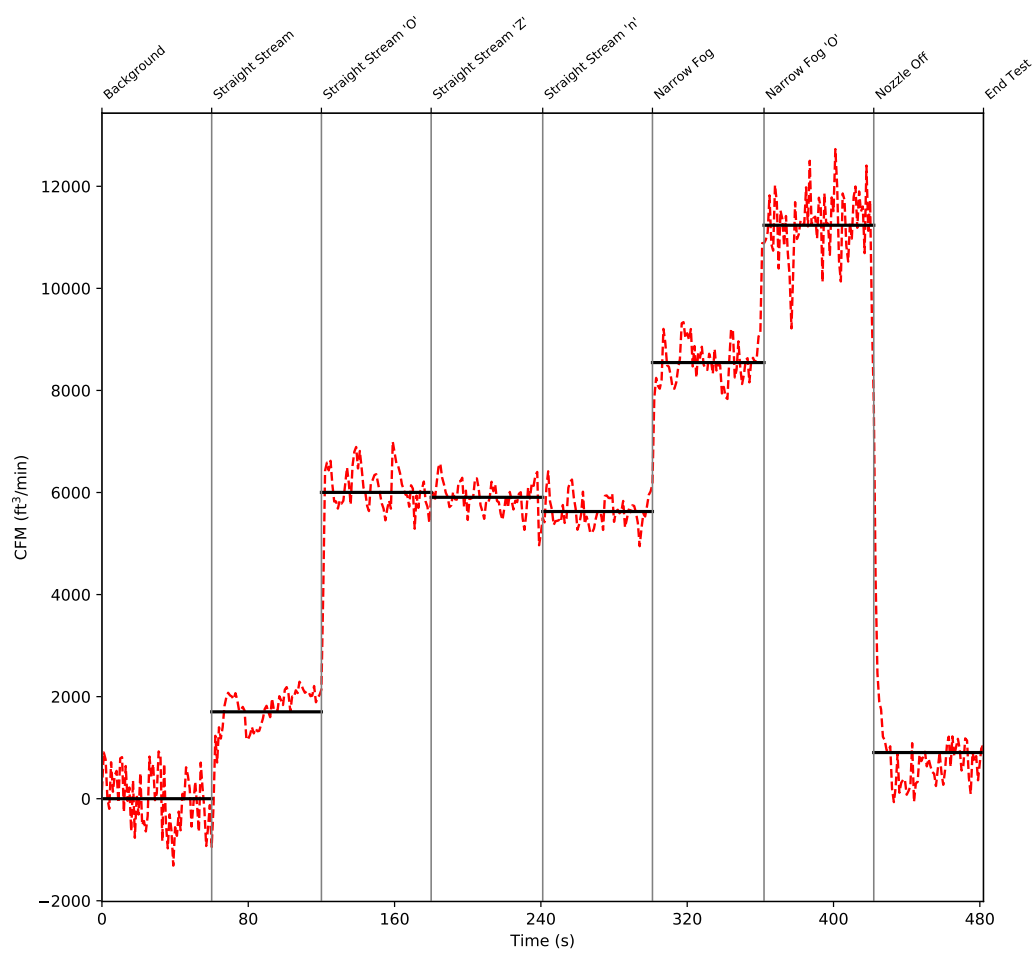

Figure 4.1: Time history of an entrainment experiment. The dashed line is the spatially-averaged flow while the solid line represents the time average in the interval bounded by the vertical time callout lines. 
Based on the discussion in Section 3.3, the uncertainty associated with measurements from the bi-directional probes is $\pm 18 \%$. Therefore, the time-averaged air entrainment data has uncertainty bars included (cf. Figure 4.2). For the data where the uncertainty bars overlap, such as those in Figure 4.2, the differences between the CFM averages cannot be differentiated.

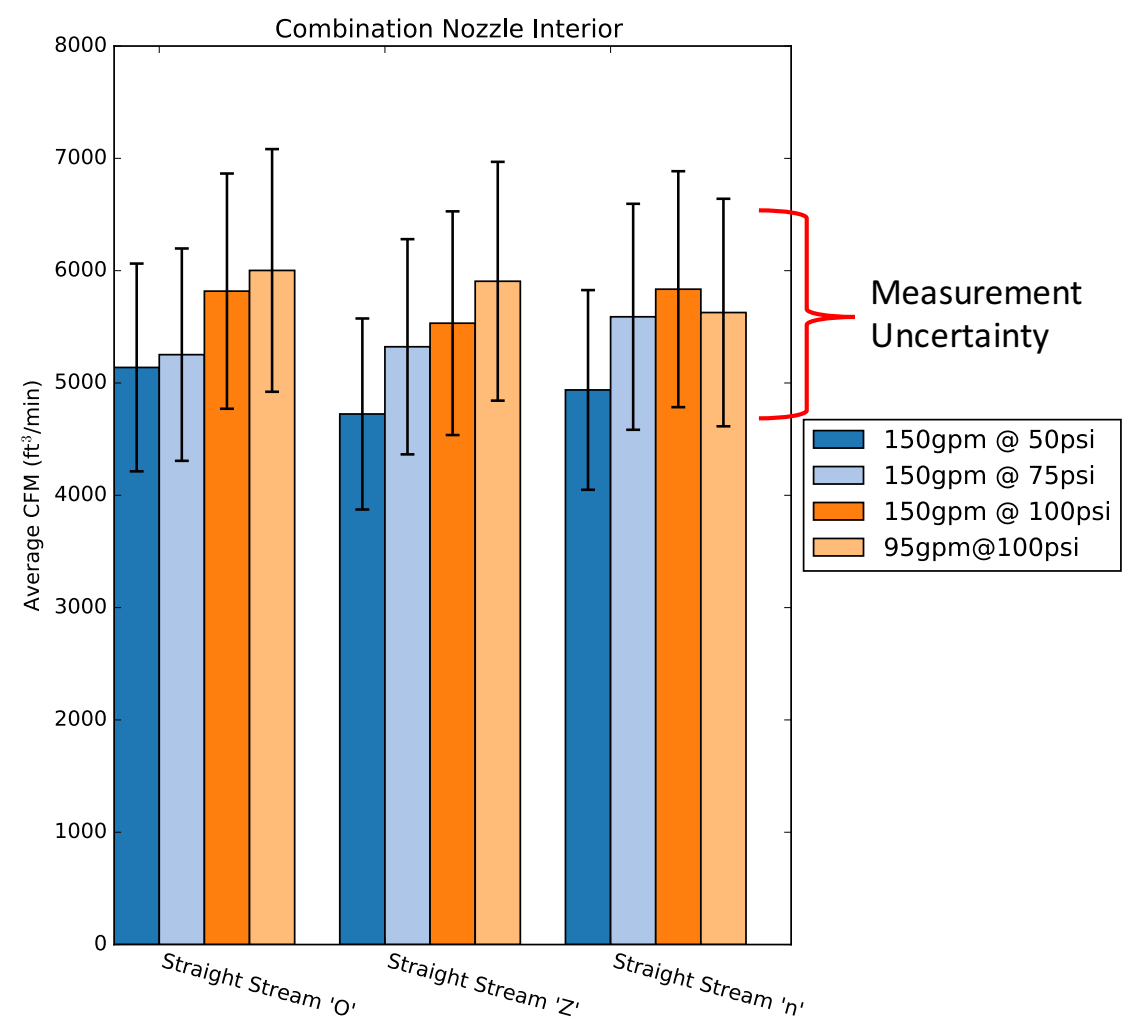

Figure 4.2: Example of bar chart comparisons with uncertainty.

The ventilation configuration of the structure used open double doors on the first and second floor. With this structure configuration, the hose stream type, nozzle pattern, flow location, flowrate and pressure, and hoseline size diameter were varied. Table 4.1 shows a list of parameters studied for this set of experiments.

The time history of air entrainment (similar to Figure 4.1) along with the average air entrainment during each event within each of the experiments conducted for this study are included in Appendix A. 
Table 4.1: Air Entrainment Experiments

\begin{tabular}{lclcccc}
\hline Location & Line Size (in) & Nozzle Type & Tip Size & Flow Rate & Pressure & Manufacturer \\
\hline Interior & $13 / 4$ & Combination & 95 & 100 & $\checkmark$ \\
Interior & $13 / 4$ & Combination & 150 & 50 & $\checkmark$ \\
Interior & $13 / 4$ & Combination & 150 & 75 & $\checkmark$ \\
Interior & $13 / 4$ & Combination & & 150 & 100 & $\checkmark$ \\
Interior & $13 / 4$ & Smooth Bore & $7 / 8$ & 150 & 50 & $\checkmark$ \\
Interior & $13 / 4$ & Smooth Bore & $15 / 16$ & 180 & 50 & $\checkmark$ \\
Interior & $13 / 4$ & Smooth Bore & 1 & 210 & 50 & $\checkmark$ \\
\hline Interior & $21 / 2$ & Combination & & 250 & 50 & \\
Interior & $21 / 2$ & Combination & & 250 & 75 & \\
Interior & $21 / 2$ & Combination & 250 & 100 & \\
Interior & $21 / 2$ & Smooth Bore & $11 / 8$ & 260 & 50 & \\
Interior & $21 / 2$ & Smooth Bore & $11 / 4$ & 320 & 50 & \\
\hline Exterior & $13 / 4$ & Combination & & 150 & 75 & \\
Exterior & $13 / 4$ & Smooth Bore & $15 / 16$ & 180 & 50 & \\
\hline Exterior & $21 / 2$ & Combination & & 250 & 75 & \\
Exterior & $21 / 2$ & Smooth Bore & $11 / 4$ & 320 & 50 & \\
\hline & $\checkmark$ indicates experiment was conducted for three manufacturers. See Section 4.2.
\end{tabular}




\subsection{Known Source Assessment}

To assess the bidirectional probes used in these experiments and the potential impact of structure leakage on measurements, experiments were conducted with a known source. The known source was an electric fan which is part of the Retrotec 5101 blower door, designed for residential and small commercial structures [11]. On the first floor, one of the double doors on the north side of the structure (Figure 3.2) was closed and in the open door, the blower door was setup. An aluminum frame together with a cloth panel snapped together to seal the doorway. The fan was installed in the cloth panel and provided the source airflow in cubic feet per minute (CFM). A calibrated speed controller was utilized to set the fan at $25 \%, 50 \%, 75 \%$ and $100 \%$ of its capacity as well as monitor the volumetric flowrate of air the fan was moving in CFM.

The double doors on the second floor (Figure 3.3) were the exhaust openings and the exhaust conditions were varied so as to quantify the impact of a single door open and double doors open. The single door was 36 in by 80 in ( $2880 \mathrm{sq}$ in) and the double door was 72 in by 80 in ( $5760 \mathrm{sq}$ in). Figures 4.3 and 4.4 show the spatial average air entrainment over time, the time-averaged measured air entrainment for the 4 fan settings, and the fan controller output CFM for a single exhaust door and the double exhaust door, respectively.

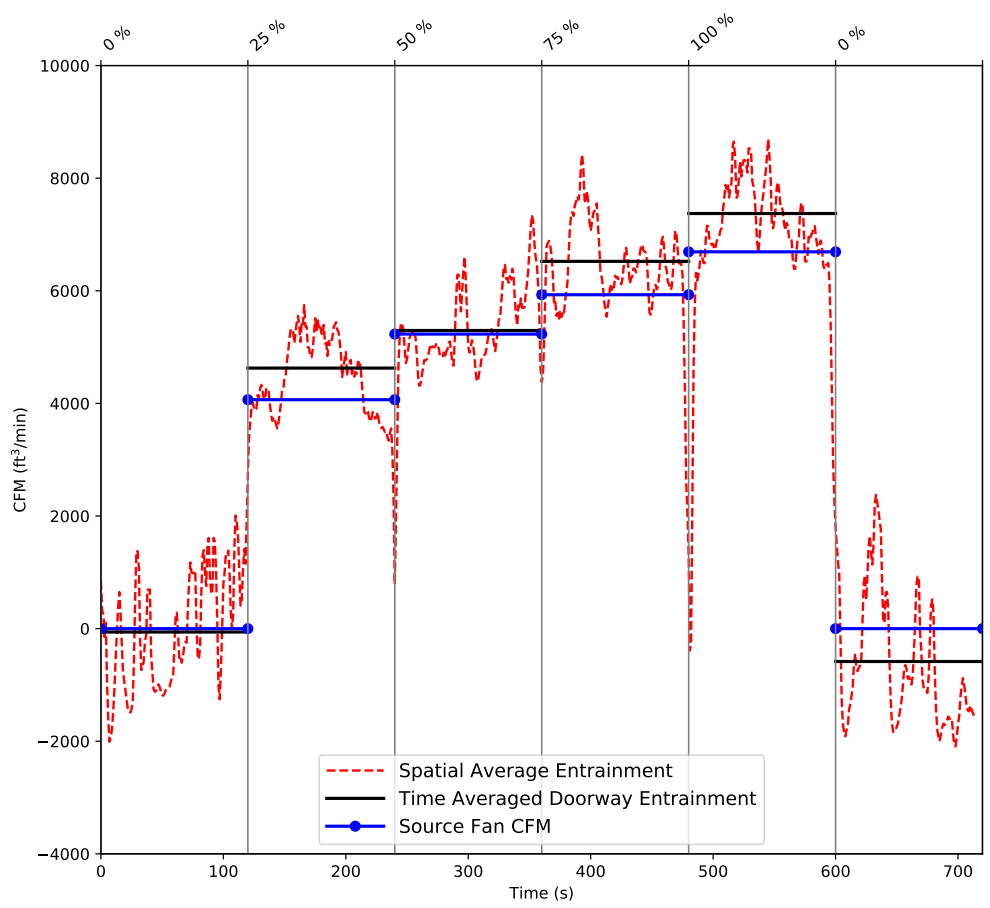

Figure 4.3: Time history of a known source entrainment experiment with a single door exhaust vent. The dashed line is the spatially-averaged flow while the solid lines represent the time averages in the interval bounded by the vertical fan percentage callout lines. 


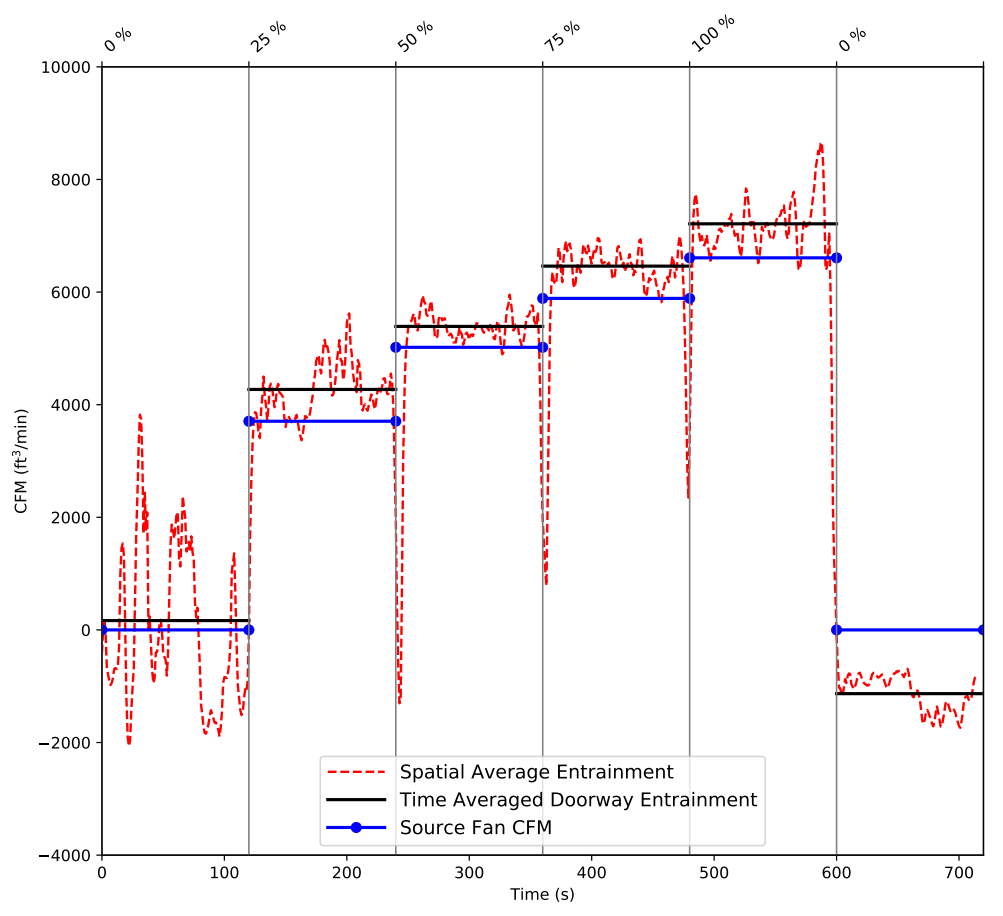

Figure 4.4: Time history of known source entrainment experiment with a double door exhaust vent. The dashed line is the spatially-averaged flow while the solid lines represent the time averages in the interval bounded by the vertical fan percentage callout lines.

Three experiments were conducted with the single exhaust door and two experiments were conducted with the double exhaust door. The air entrainment values for the replicates in both exhaust cases were similar, which indicated that the tests were repeatable. The magnitude of the air entrainment for single door opening combined with leakage through the structure was sufficient to not restrict the fan flow at the $100 \%$ output setting as the values were similar to experiments with two exhaust doors open. The peak standard error of the measured air entrainment CFM compared to the source fan CFM was approximately $14 \%$ for the single exhaust door and $23 \%$ for the double exhaust door. Based on these results, using the $\pm 18 \%$ uncertainty discussed in Section 3.3, is acceptable. The time history CFM and event time-averaged CFM plots for all of the replicates are included in Appendix B.

\subsection{Manufacturer Comparison}

Experiments varying pressure/flow rate, hose stream type, and nozzle movement were conducted to quantify potential differences in air entrainment associated with using nozzles from three different manufacturers (MFI, MFII, and MFIII). Table 4.2 shows the configurations examined. For all three hose stream types, both a fixed pattern and an ' $\mathrm{O}$ ' pattern were used from the interior position. 
Table 4.2: Manufacturer Comparison Experiments

\begin{tabular}{cccc}
\hline Hose Stream Type & Tip Size & Flow Rate & Pressure \\
\hline Straight Stream & & 150 & 50 \\
Straight Stream & & 150 & 75 \\
Straight Stream & & 150 & 100 \\
Narrow Fog & & 150 & 50 \\
Narrow Fog & & 150 & 75 \\
Narrow Fog & & 150 & 100 \\
Smooth Bore & $7 / 8$ & 150 & 50 \\
Smooth Bore & $15 / 16$ & 180 & 50 \\
Smooth Bore & 1 & 210 & 50 \\
\hline
\end{tabular}

Figure 4.5 shows the average flow rate (CFM) for both the straight stream and narrow fog hose stream types with fixed and ' $O$ ' patterns under three different pressures: 50 psi, 75 psi, and 100 psi. Figure 4.6 shows the average flow rate for three smooth bore nozzles; a 7/8 in tip with $150 \mathrm{gpm}$ at $50 \mathrm{psi}$, a $15 / 16$ in tip with $180 \mathrm{gpm}$ at $50 \mathrm{psi}$, and a 1 in tip with $210 \mathrm{gpm}$ at $50 \mathrm{psi}$ for both a fixed and 'O' pattern.

For the straight streams and narrow fog streams with both fixed patterns and ' $O$ ' patterns, the air entrainment for the three manufacturers was within the experimental uncertainty of the measurement for all three pressures (Figure 4.5). For the smooth bore streams, the three manufactures were generally within the experimental uncertainty of the air entrainment measurements (Figure 4.6). MFI had slightly lower average CFM for a fixed stream with $15 / 16$ in tip with $180 \mathrm{gpm}$ at 50 psi and an ' $\mathrm{O}$ ' Pattern with a 1 in tip with $210 \mathrm{gpm}$ at 50 psi. While these two cases had lower average air entrainment, when assessing the magnitude of the differences over the set of comparisons made, the three manufacturers are similar. As a result, the experiments designed to assess the configuration variables all used nozzles from MFI. 

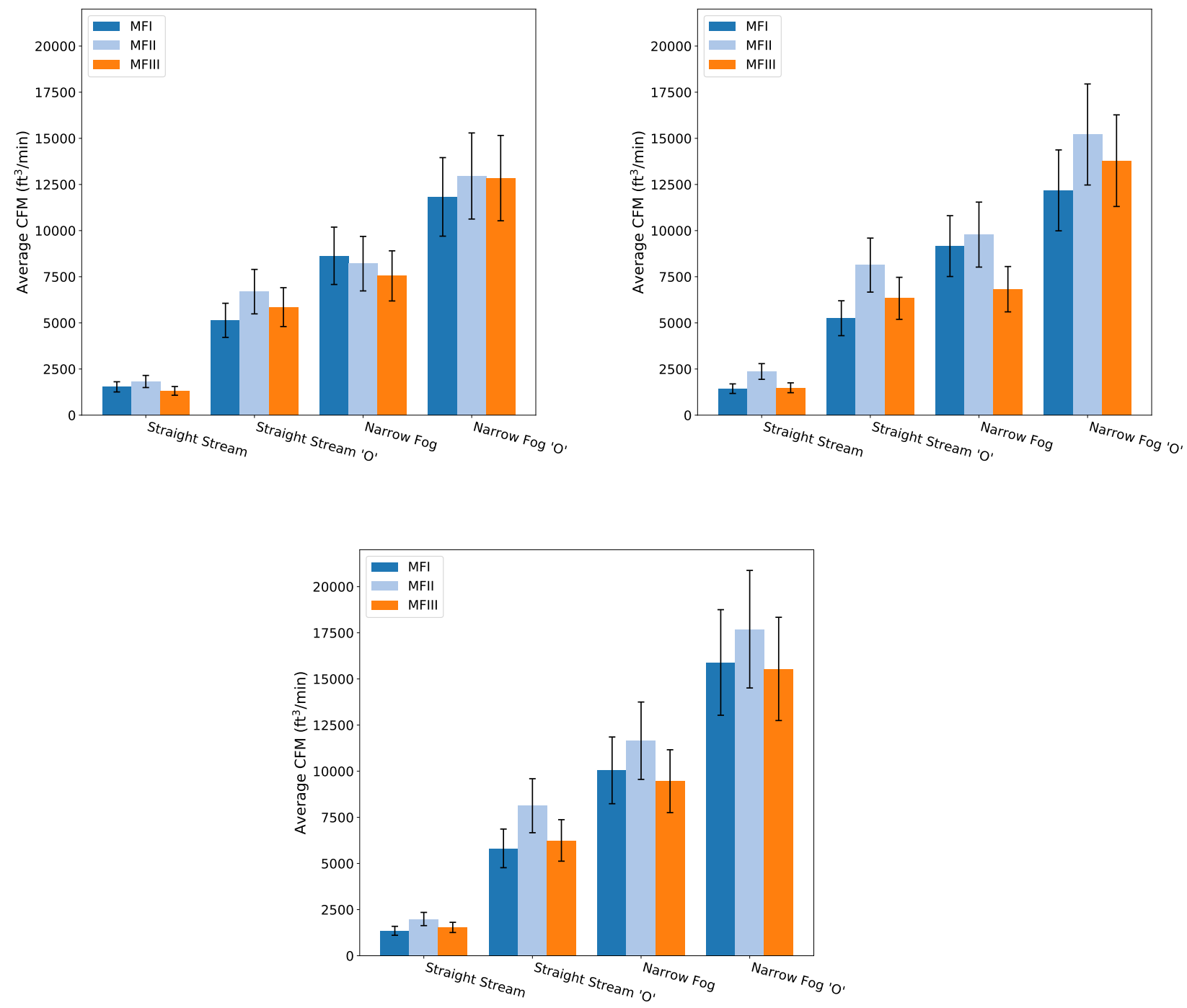

Figure 4.5: Comparison of air entrainment results of three manufacturers for straight stream and narrow fog stream in fixed and ' $\mathrm{O}$ ' patterns with $150 \mathrm{gpm}$ and $50 \mathrm{psi}$ (upper left), 75 psi (upper right), and 100 psi (bottom). 

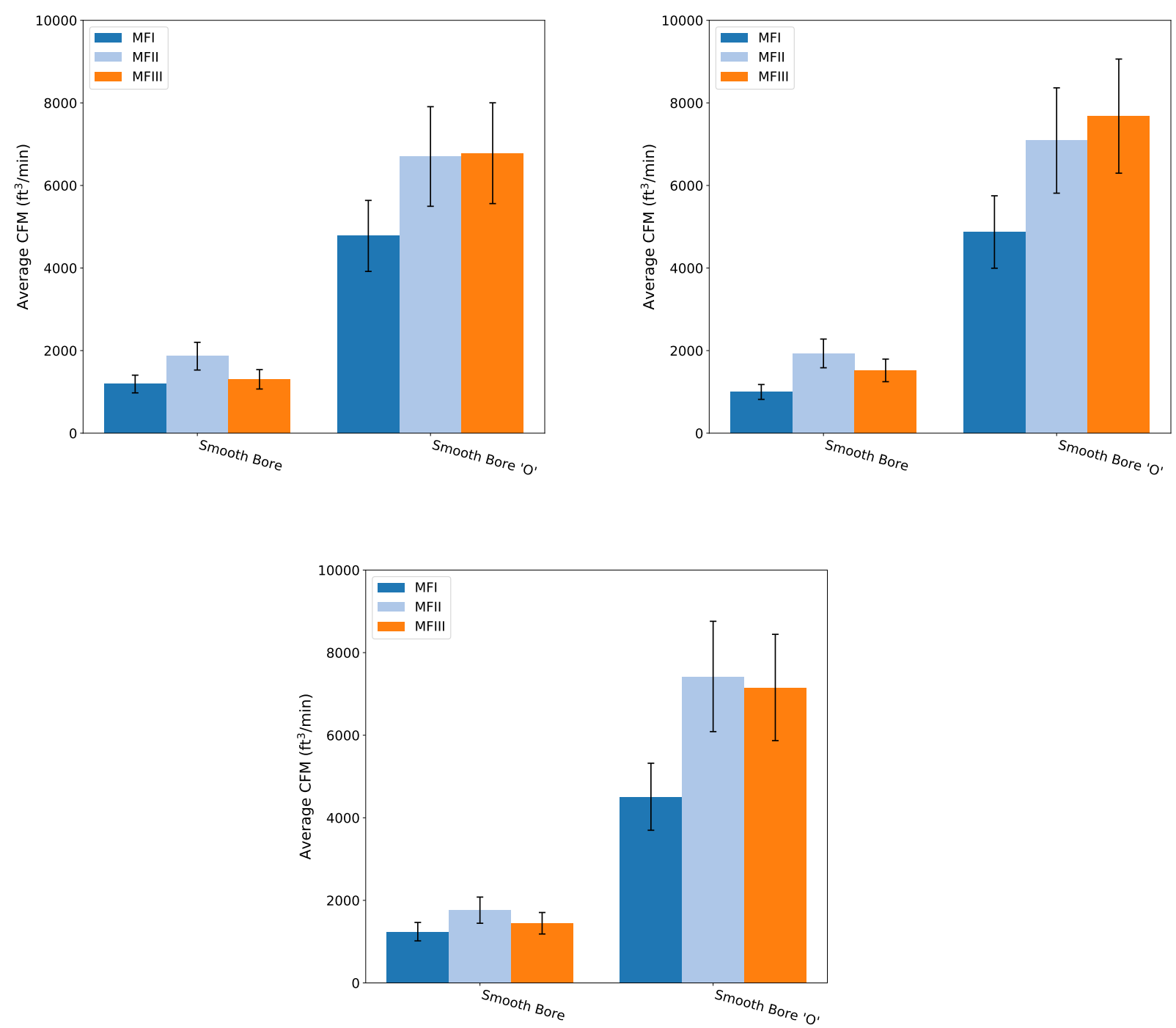

Figure 4.6: Comparison of air entrainment results of three manufacturers for smooth bore stream in fixed and 'O' patterns with 7/8 in tip with $150 \mathrm{gpm}$ at $50 \mathrm{psi}$ (upper left), with 15/16 in tip with $180 \mathrm{gpm}$ at $50 \mathrm{psi}$ (upper right), and 1 in tip with $210 \mathrm{gpm}$ at $50 \mathrm{psi}$ (bottom). 


\section{Results}

The intent of the air entrainment experiments was to determine the average volumetric flow of air (CFM) within the compartment as a function of several common fire service nozzle configurations and application locations. Recall, the location of the air entrainment measurement within the compartment was achieved using an array of bi-directional probes (Section 3.4).

\subsection{Comparison of the Impact of Hose Stream Type}

The hose stream type comparison experiments were designed to quantify differences in average air entrainment in cubic feet per minute (CFM) from a straight stream, smooth bore stream, and a narrow fog stream. From the interior position, the three hose stream types were compared with a fixed pattern and an 'O' to determine differences from a static (fixed pattern) flow and if moving the stream ('O' pattern) changed the relationship between the stream types. Figures 5.1 and 5.2 show the average air entrainment values for the fixed pattern and ' $\mathrm{O}$ ' pattern hose stream comparisons, respectively.

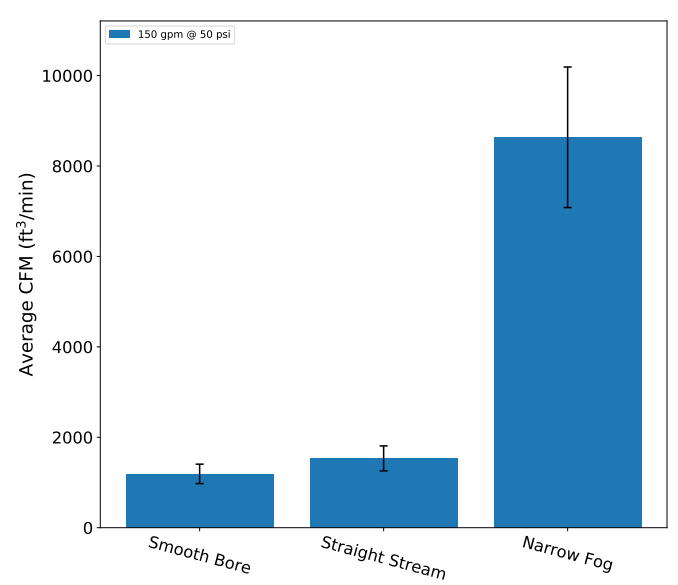

Figure 5.1: Air entrainment for three hose stream types: smooth bore, straight stream, and narrow fog with a fixed pattern from the interior position for a flow rate of $150 \mathrm{gpm}$ at $50 \mathrm{psi}$.

In both the fixed and ' $\mathrm{O}$ ' pattern comparisons, the smooth bore stream and straight stream had similar values of air entrainment within the measurement uncertainty. For the fixed pattern, the narrow fog entrained approximately six times as much air as the straight stream and smooth bore stream. The straight stream and smooth bore stream also had similar air entrainment values with an 'O' pattern compared to the narrow fog which entrained approximately 2.5 times more air. Note that with the ' $\mathrm{O}$ ' pattern, all three hose streams had increased air entrainment. Further discussion of nozzle movement is included in Section 5.2). Finally, observe that the fixed pattern narrow fog 


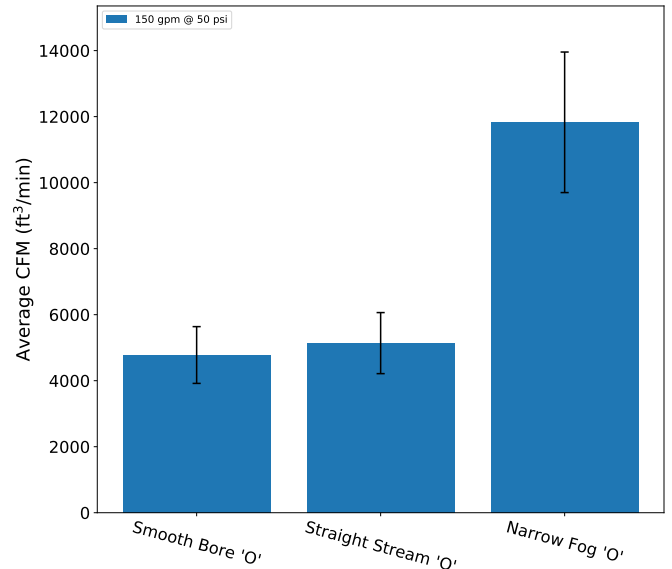

Figure 5.2: Air entrainment for three hose stream types: smooth bore, straight stream, and narrow fog with an 'O' pattern from the interior position for a flow rate of $150 \mathrm{gpm}$ at $50 \mathrm{psi}$.

still entrained approximately 2 times more air than the smooth bore stream and straight stream with an 'O' pattern. 


\subsection{Comparison of Impact of Nozzle Movement}

Common nozzle movements used in the fire service are the 'O', ' $\mathrm{Z}$ ', and ' $\mathrm{n}$ ' patterns. Differences in the patterns were examined using a straight stream and narrow fog stream from a combination nozzle as well as a smooth bore nozzle. The experiments were conducted from the interior position at a fixed setback distance of $12 \mathrm{ft}$ from the external vent. For the smooth bore stream, straight stream and narrow fog stream, a fixed nozzle pattern was compared to an 'O' pattern. The combination nozzle flowed $150 \mathrm{gpm}$ at $50 \mathrm{psi}$; to have an equivalent flow from the smooth bore nozzle, a $7 / 8$ in tip was used. Figure 5.3 shows the average air entrainment (CFM) for a fixed pattern stream compared to a stream with an 'O' pattern for the three hose stream types.
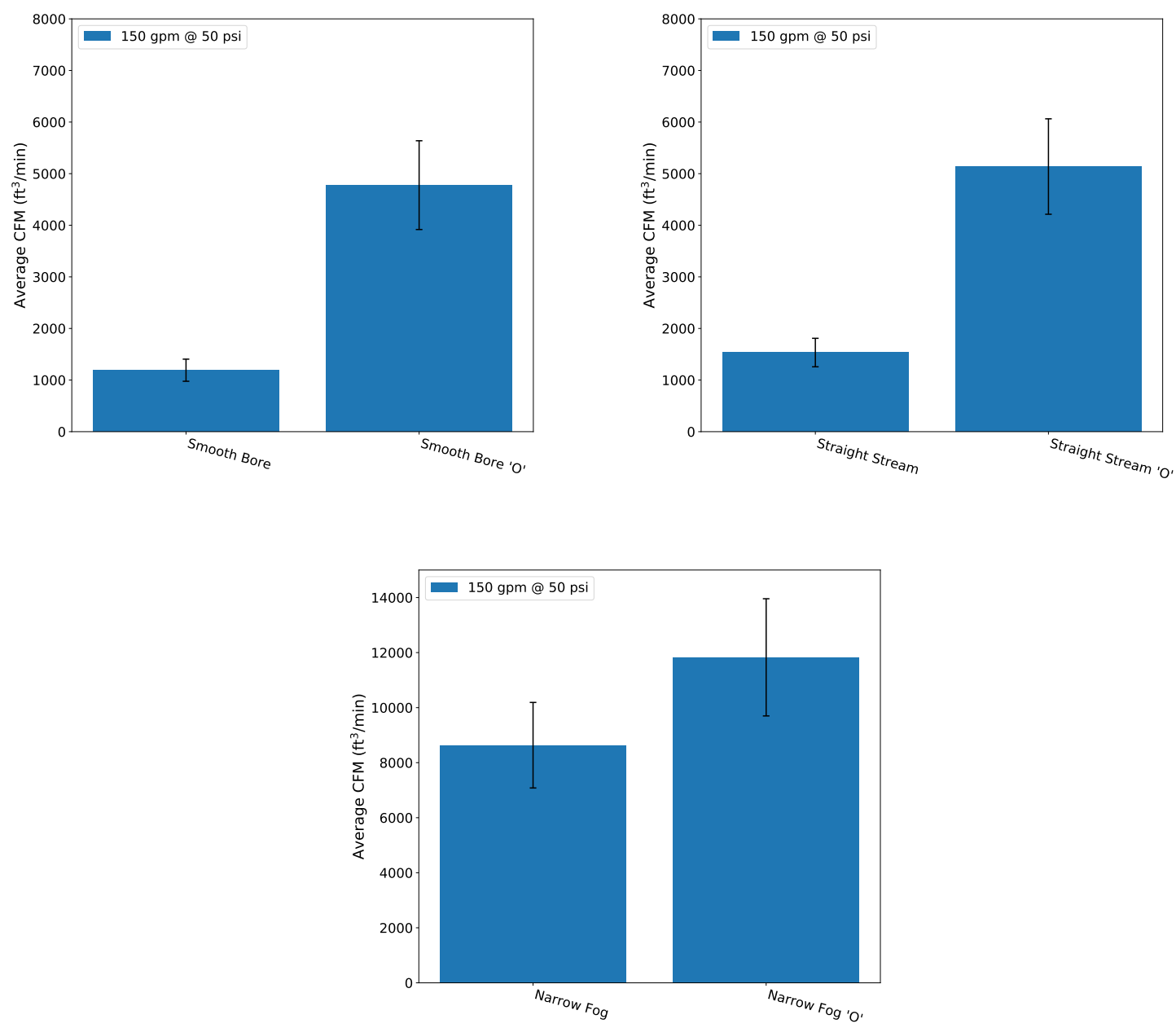

Figure 5.3: Air entrainment for three hose stream types comparing fixed versus moving patterns: smooth bore stream (upper left), straight stream (upper right), and narrow fog (bottom).

These experiments showed that for both the straight stream and smooth bore stream, when moved, the air entrainment was approximately 3.5 times more air compared to the fixed pattern. For the narrow fog stream, Figure 5.3 shows that the ' $\mathrm{O}$ ' pattern stream had a higher average air entrain- 
ment compared to fixed pattern. However, the values fall within the measurement uncertainty and therefore definitive conclusions about the differences between the fixed and 'O' pattern cannot be drawn.

Additionally, for both the straight stream and smooth bore stream, air entrainment from ' $\mathrm{O}$ ', ' $\mathrm{Z}$ ', and 'n' patterns were compared to quantify the potential impact that movement pattern could have. Figure 5.4 illustrates the three patterns and Figure 5.5 shows the average air entrainment for the three movement patterns for a smooth bore stream and straight stream.

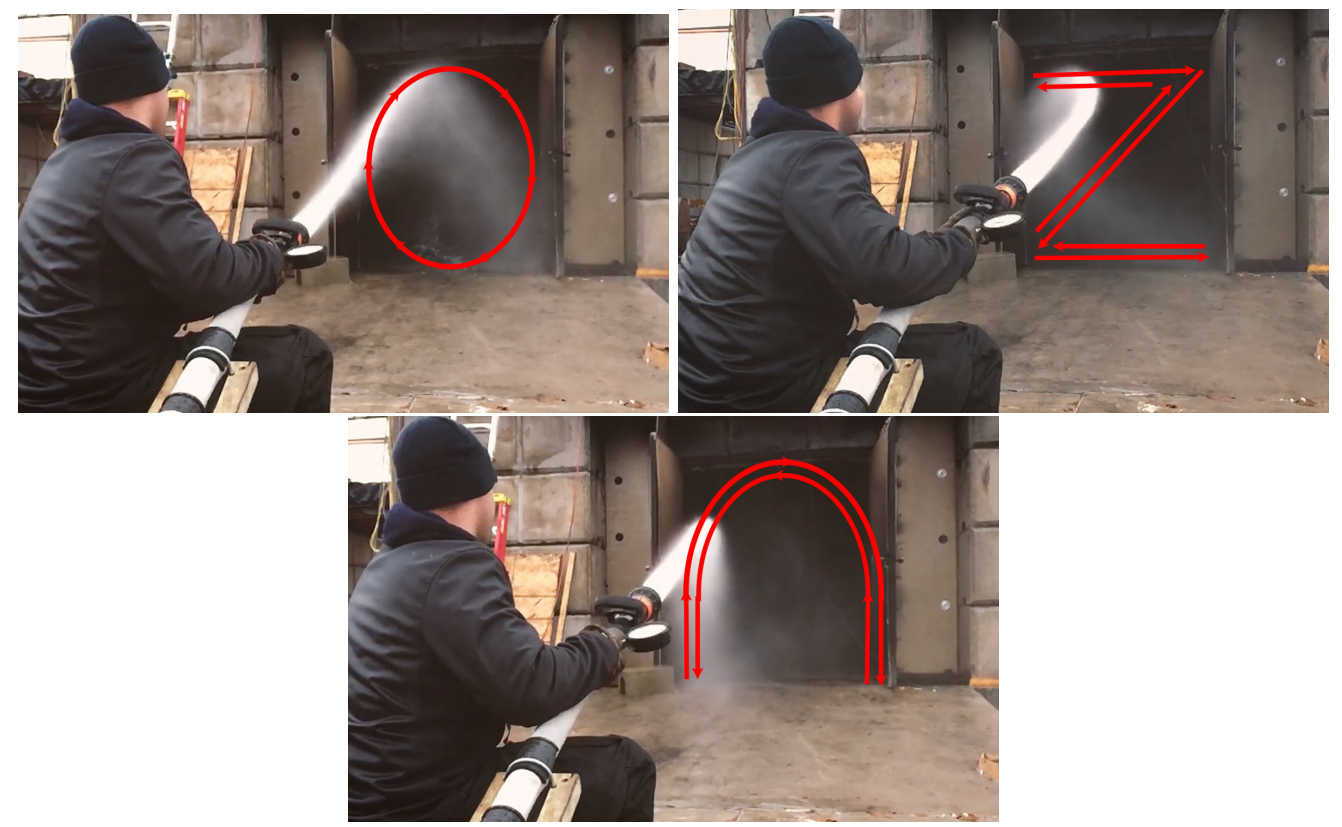

Figure 5.4: Typical Nozzle Patterns - 'O' (top left), 'Z' (top right), and 'n’ (bottom)
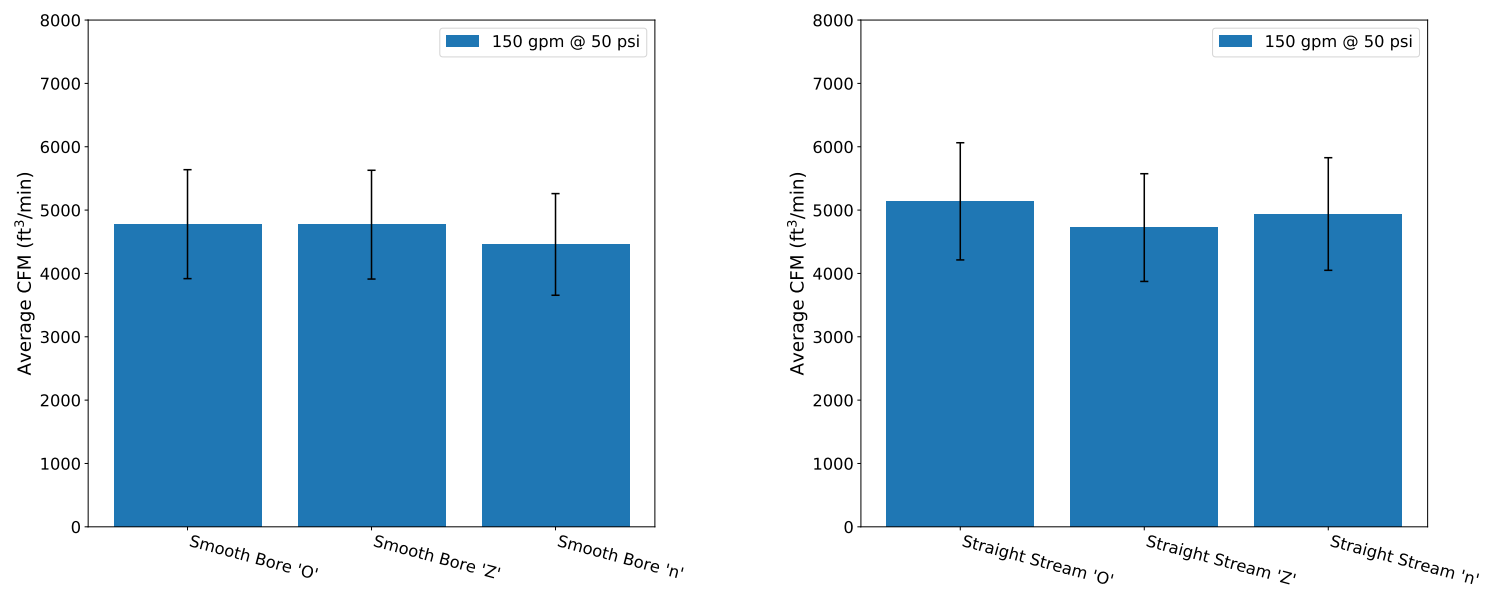

Figure 5.5: Air entrainment for three nozzle movement patterns: 'O', ' $Z$ ', and 'n' for a smooth bore stream (left) and straight stream (right). 
The experiments showed that for both the straight stream and smooth bore stream that the movement pattern of nozzle had little noticeable impact on air entrainment as all three patterns resulted in similar volumetric flows of air through the measurement location. To further test nozzle movement, an 'O' pattern was compared to 'Spray and Pray' technique in which the nozzle operator moved the hose stream across the ventilation opening as fast as possible with no discernible pattern. Figure 5.6 shows the comparison between the ' $O$ ' pattern and 'Spray and Pray' for a 1 in smooth bore nozzle that flowed $210 \mathrm{gpm}$ at $50 \mathrm{psi}$ and that the nozzle pattern does not impact the magnitude of air entrainment.

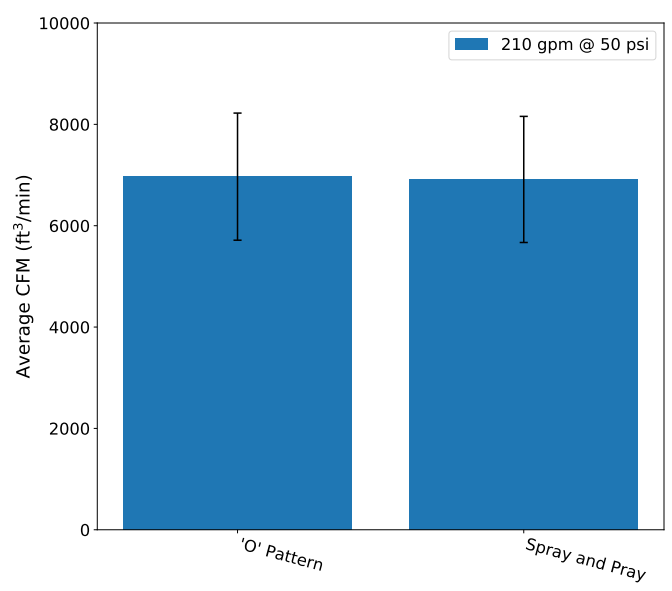

Figure 5.6: Figure showing common pattern compared to no discernible pattern for an interior 1.5 in smooth bore nozzle with a 1 in tip.

The final nozzle movement experiments were conducted to quantify potential differences in air entrainment when a smooth bore nozzle with a flow rate of $210 \mathrm{gpm}$ and pressure of 50 psi was rotated with a ' $\mathrm{O}$ ' pattern at different rotation speeds. Using a metronome, the 'O' pattern was applied at 50,100, and 150 revolutions per minute. This test was conducted at the same interior setback distance of $12 \mathrm{ft}$ from the tip of the nozzle to the ventilation opening.

As shown in Figure 5.7, an increase in the rotation speed while applying a specified pattern yielded an increase in the air entrainment seen within the stream. Note that while there is overlap in the measurement uncertainty between $50 \mathrm{rpm}$ versus $100 \mathrm{rpm}$ and $100 \mathrm{rpm}$ versus $150 \mathrm{rpm}$, since there is a distinct difference between $50 \mathrm{rpm}$ and $150 \mathrm{rpm}$ there exists confidence to conclude that nozzle rotation speed following the same pattern can entrain additional air.

\subsection{Comparison of Impact of Pressure and Flow Rate}

The range of operating pressure and flow rate varies within the fire service from many reasons, including need (potential fire hazard), equipment, and/or preference. To determine how changes in pressure and/or flow rate influence air entrainment, experiments were conducted to quantify this 


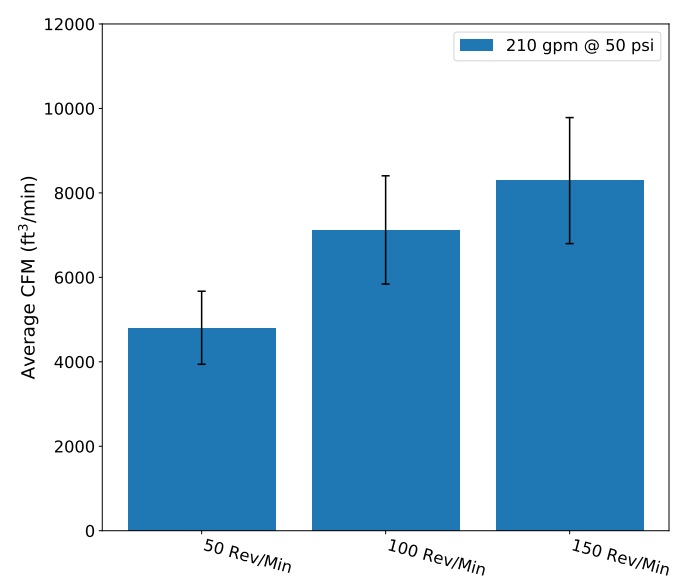

Figure 5.7: Air entrainment comparison of ' $\mathrm{O}$ ' pattern rotation rate for a 1 in. smooth bore nozzle.

impact. From the interior position (recall Section 3.4), a straight stream and narrow fog stream from a combination nozzle connected to a $13 / 4$ in hoseline examined four flow rates and a smooth bore stream also connected to a $13 / 4$ in hoseline examined three flow rates. Figures 5.8 and 5.9 show the impact of flowrate changes for the combination nozzle experiments and smooth bore nozzle experiments respectively.
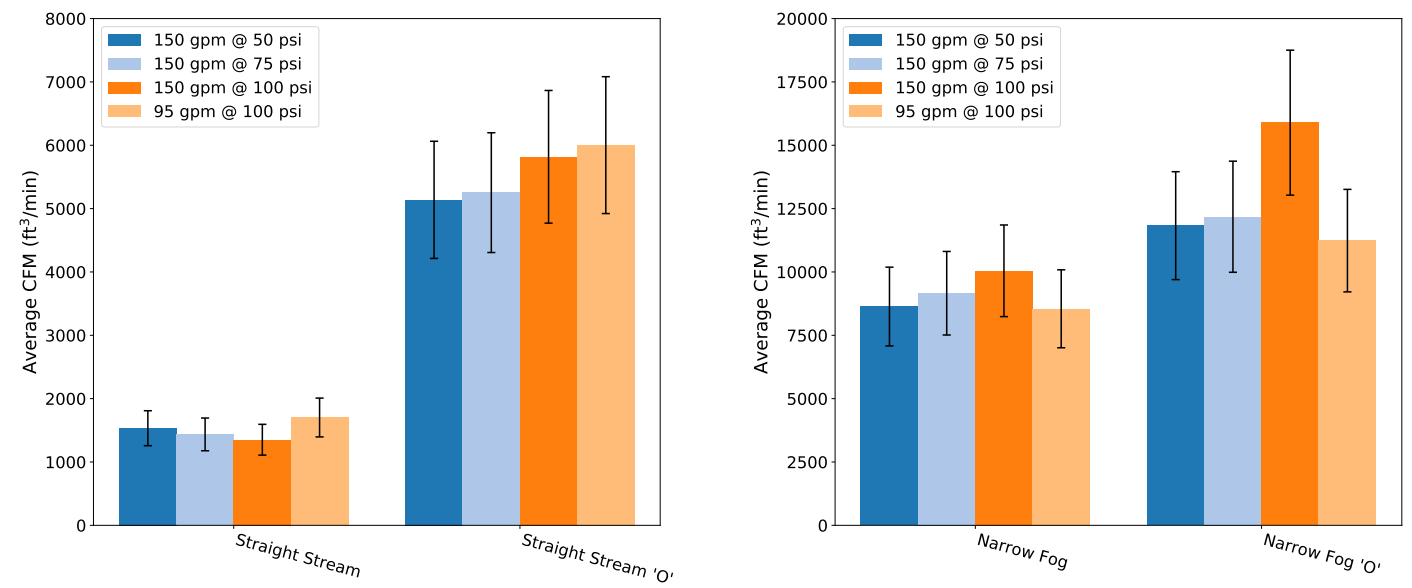

Figure 5.8: Air entrainment comparison of change in flow rate and pressure from interior position with a $13 / 4$ in line for a straight stream (left) and a narrow fog stream (right).

The average air entrainment values for the straight stream and narrow fog stream in Figure 5.8 were consistent for the $150 \mathrm{gpm}$ flowrate at $50 \mathrm{psi}, 75 \mathrm{psi}$, and $100 \mathrm{psi}$ as well as the $95 \mathrm{gpm}$ flowrate at 100 psi. For the experiments where the nozzle was rotated in an ' $\mathrm{O}$ ' pattern, the air entrainment was also similar for both hose stream types. In the case of the narrow fog stream with the ' $O$ ' pattern, the $150 \mathrm{gpm}$ flowrate at $100 \mathrm{psi}$ had a higher average air flow rate, however the value still fell within the measurement uncertainty range of the other three flowrate conditions. The smooth 


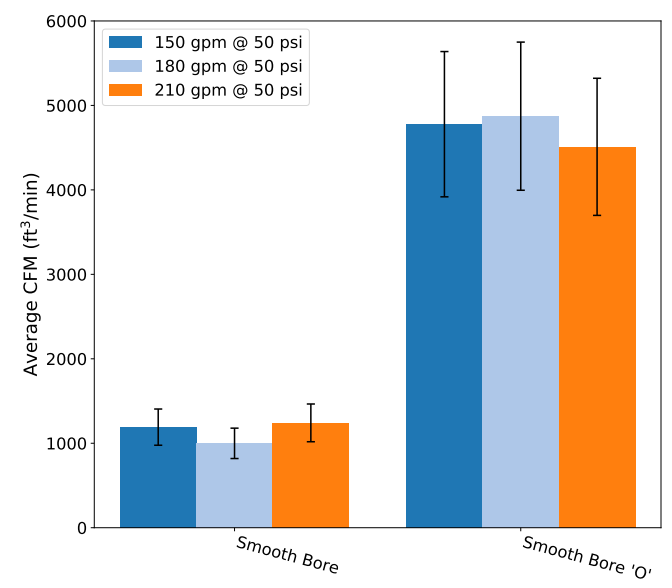

Figure 5.9: Air entrainment comparison of change in flow rate and pressure from interior position with a $13 / 4$ in line for a smooth bore stream.

bore stream also showed minimal variation as a function of the three flow rates tested: $150 \mathrm{gpm}$, $180 \mathrm{gpm}$, and $210 \mathrm{gpm}$ all at $50 \mathrm{psi}$ (Figure 5.9) for both a fixed and 'O' pattern. To further assess the impact of pressure and flowrate, Figures 5.10 and 5.11 show the average air entrainment for the interior position with a $21 / 2$ in hoseline for a combination nozzle and smooth bore nozzle.
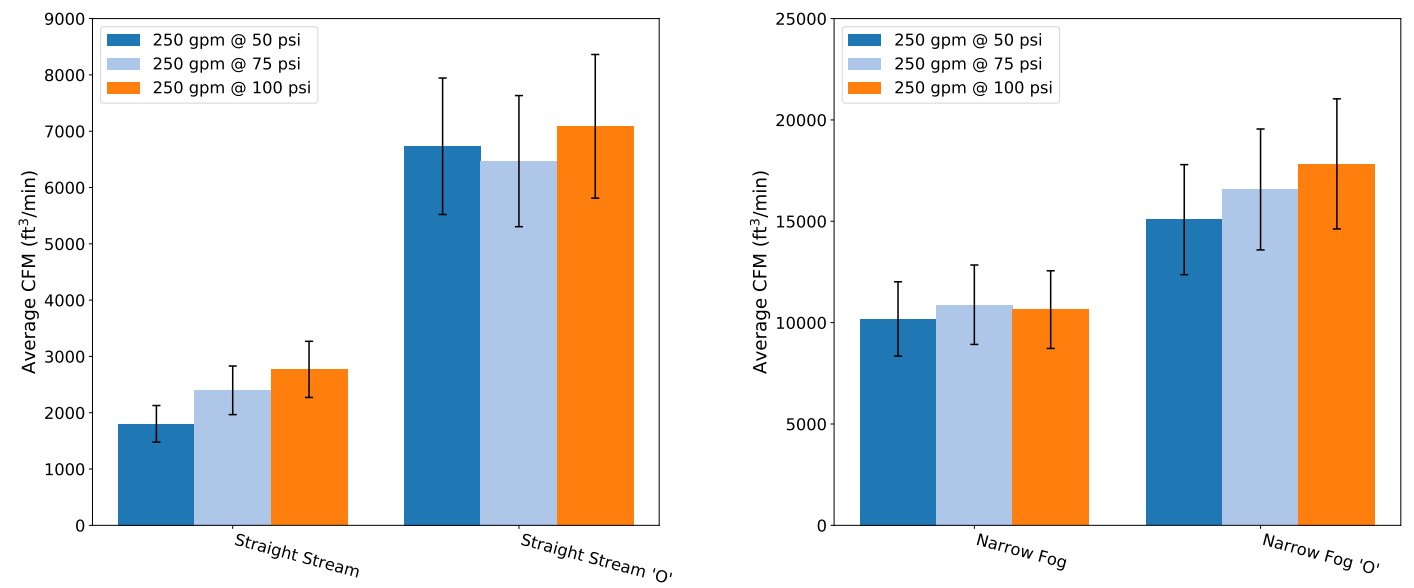

Figure 5.10: Air entrainment comparison of change in flow rate and pressure from interior position with a $21 / 2$ in line for a straight stream (left) and a narrow fog stream (right).

Similar to the $13 / 4$ in hoseline, there was negligible impact on the average air entrainment when changing pressure and flow rate for the $21 / 2$ in hoseline. For the straight stream and narrow fog stream increasing the pressure from $50 \mathrm{psi}$ to $75 \mathrm{psi}$ to $100 \mathrm{psi}$ for a $250 \mathrm{gpm}$ flow, the average air entrainment values had minimal change. The fixed nozzle pattern for the smooth bore nozzle showed an increase for the $320 \mathrm{gpm}$ flow at $50 \mathrm{psi}$ compared to the $260 \mathrm{gpm}$ at $50 \mathrm{psi}$. However 


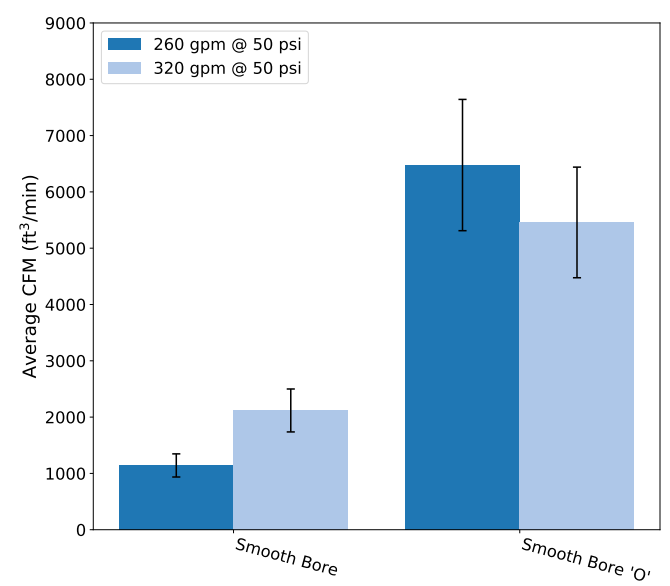

Figure 5.11: Air entrainment comparison of smooth bore nozzle flow rate and pressure from interior position with a $21 / 2$ in line.

when an 'O' pattern was applied, the average air entrainment values were similar (within the experimental uncertainty).

To complete the assessment of the impact of flowrate and pressure on air entrainment from the interior position, the results from $13 / 4$ in hoseline experiments were compared against those that used a 2 1/2 in hoseline. Figures 5.12 and 5.13 show the comparison between the two hoselines for a combination nozzle and smooth bore nozzle, respectively.
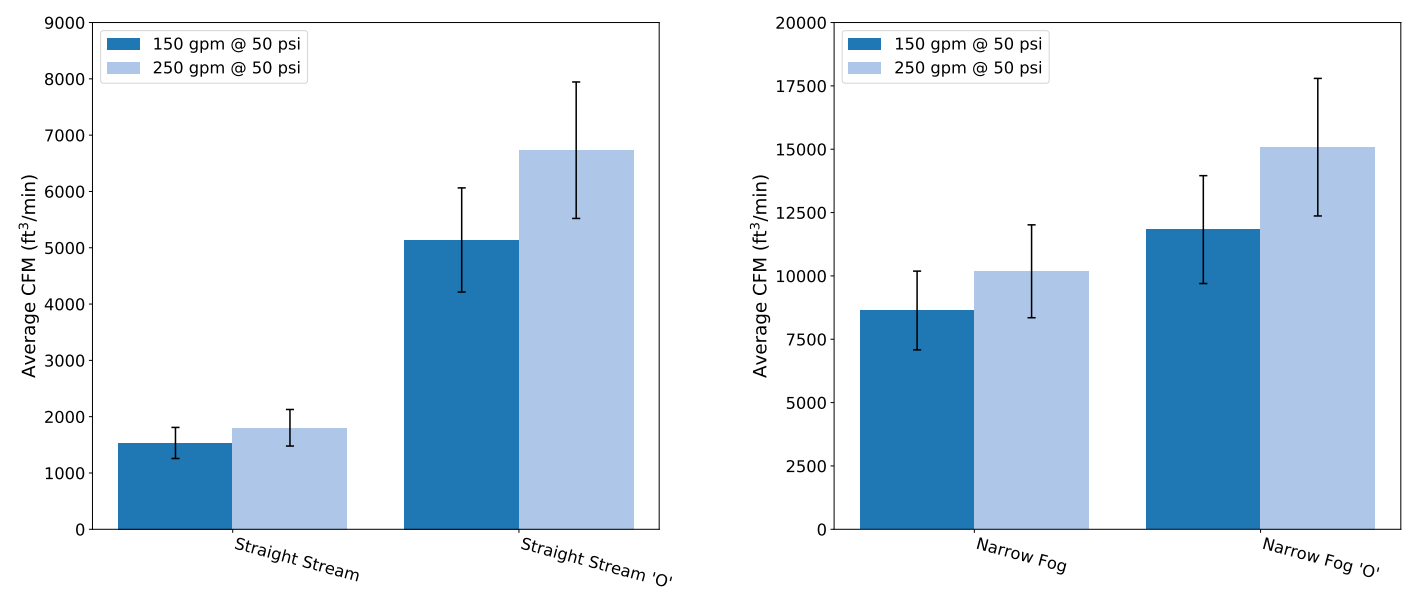

Figure 5.12: Air entrainment comparison of a straight stream (left) and narrow fog stream (right) as a function of flow rate and pressure from interior position with a $13 / 4$ in line (180 gpm at 50 psi) to a $21 / 2$ in line $(320 \mathrm{gpm}$ at $50 \mathrm{psi})$.

In Figure 5.12, the average air entrainment from a $13 / 4$ in hose line with a combination nozzle that flowed $150 \mathrm{gpm}$ at 50 psi was compared to a $21 / 2$ in hoseline with a combination nozzle 


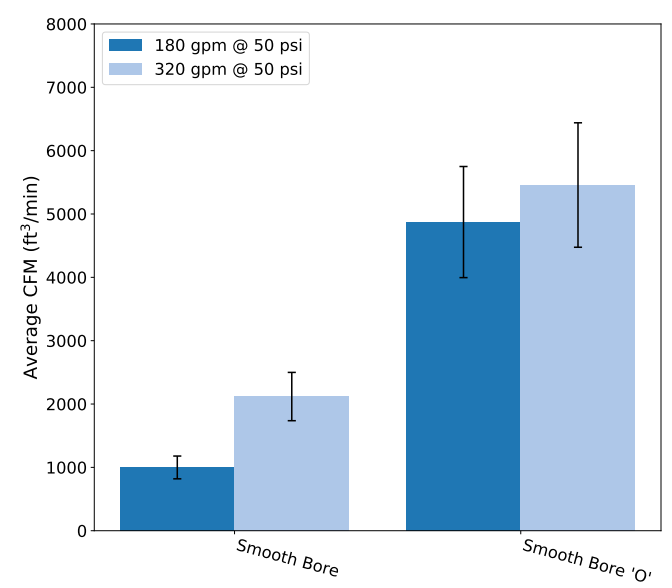

Figure 5.13: Air entrainment comparison of smooth bore nozzle flow rate and pressure from interior position with a $13 / 4 \mathrm{in}$. line (180 gpm at $50 \mathrm{psi})$ to a $21 / 2$ in line (320 gpm at $50 \mathrm{psi})$.

that flowed $250 \mathrm{gpm}$ at $50 \mathrm{psi}$. Straight streams and narrow fog streams were analyzed for a fixed pattern as well as an ' $O$ ' pattern. In all four cases, the increase in flow rate from the larger supply line had negligible increase in air entrainment as all average values were within the measurement uncertainty of each other. Figure 5.13 shows the comparison of average air entrainment for a $15 / 16$ in tip smooth bore on a $13 / 4$ in hoseline that flowed $180 \mathrm{gpm}$ at 50 psi to a $11 / 4$ in tip smooth bore on a $21 / 2$ in hoseline that flowed $320 \mathrm{gpm}$ at 50 psi. Similar to the two flowrates with the fixed pattern smooth bore in Figure 5.11, the $320 \mathrm{gpm}$ at 50 psi configuration had a higher average air entrainment flow compared to the lesser flowrate, in this case $180 \mathrm{gpm}$ at 50 psi. Comparing the $180 \mathrm{gpm}$ at $50 \mathrm{psi}$ in Figure 5.13 to the $260 \mathrm{gpm}$ at $50 \mathrm{psi}$ in Figure 5.11 shows that those two cases are similar and that the hoseline size does not necessarily mean there will be an increase in air entrainment. The 'O' pattern shows air entrainment values which are similar for the two hoseline sizes

For an exterior position, a smooth bore stream from a $13 / 4$ in. hoseline with a 15/16 in. tip that flowed $180 \mathrm{gpm}$ at $50 \mathrm{psi}$ was compared to smooth bore stream with a $11 / 4 \mathrm{in}$. tip on a $21 / 2 \mathrm{in}$. hoseline that flowed $320 \mathrm{gpm}$ at $50 \mathrm{psi}$. The purpose of this comparison was to ensure that a change in flowrate was consistent as a function of flow position. Figure 5.14 shows the two smooth bore streams for a fixed pattern and 'O' pattern.

Similar to the interior experiments, the change in flowrate associated with increasing the hoseline size and tip size for a smooth bore stream did not have a measurable difference (values were within measurement uncertainty). Also, comparable to the interior experiments, the rotation of the stream in an ' $\mathrm{O}$ ' pattern increased the air entrainment similarly for both flowrates. 


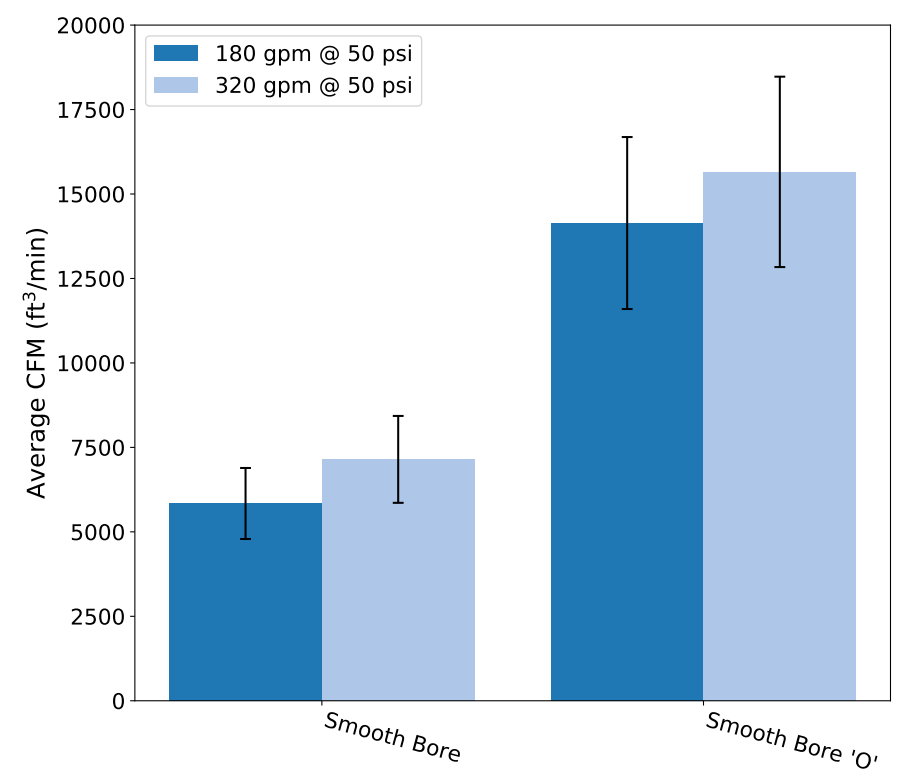

Figure 5.14: Air entrainment comparison of smooth bore nozzle flow rate and pressure from exterior position with a $13 / 4$ in line (180 gpm at $50 \mathrm{psi})$ to a $21 / 2$ in line (320 gpm at $50 \mathrm{psi})$. 


\section{Discussion}

\subsection{Understanding the Basics of Air Entrainment}

As a drop of water moves though air it compresses some of the air in front of it, causing a high pressure ahead of the droplet and low pressure behind the droplet. The low pressure behind the droplet, along with the turbulence created, results in a drag force behind the droplet. This drag force pulls air along behind the droplet as it moves.

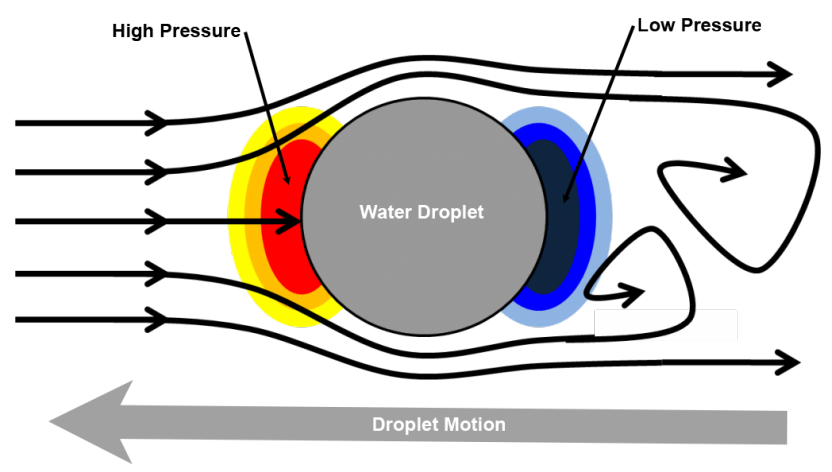

Figure 6.1: Air flows around a droplet.

This same concept can be applied to fire service hose streams. As the water from the stream flows through air it displaces air in front of it, creating lower pressure behind the water and pulling air along its path. A practical application of this in the fire service is the use of a hose stream for ventilation (hydraulic ventilation). Water is directed out an opening and the as the stream breaks up the droplets pull the smoke through the same opening to ventilate the structure.

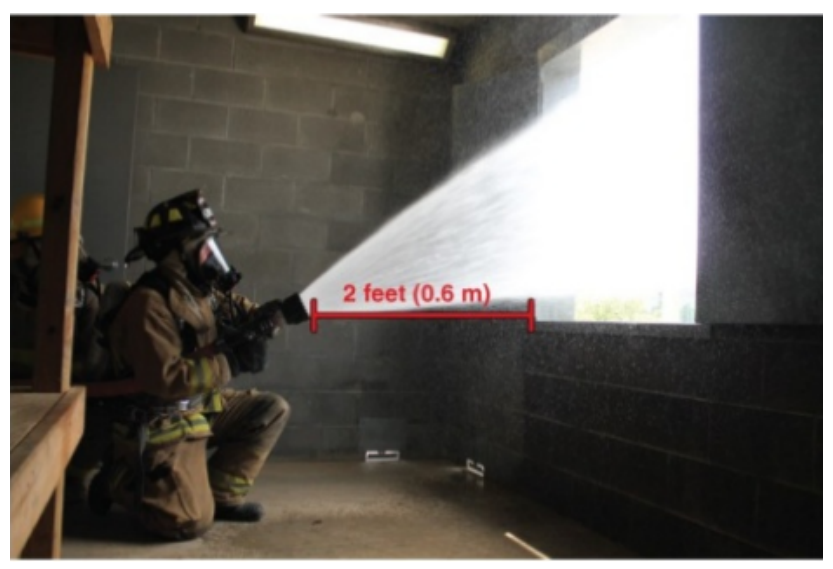

Figure 6.2: Hydraulic ventilation. 
Understanding the principals of air entrainment can help firefighters understand how their action will move more or less air. Entrainment is based on several different factors including hose stream type, stream length, and nozzle movement, many of which are choices for the firefighter operating the nozzle.

\subsection{Smooth Bore Streams \& Straight Streams Have Equivalent Air Entrainment}

Smooth bore nozzles have often been thought of as having more 'penetration' then straight stream nozzles [12]. As far as air entrainment is concerned, there is no practical difference between a smooth bore nozzle and a combination nozzle set to straight stream. The amount of dispersion (break up) in the two streams is similar, which results in a similar air entrainment. Figure 6.3 shows all of the $13 / 4$ in. smooth bore and straight stream nozzles tested when operating in the fixed position. The values from the 21 different nozzle configurations show no discernible difference between the manufacturers, nozzle type, or pressure and flowrate.

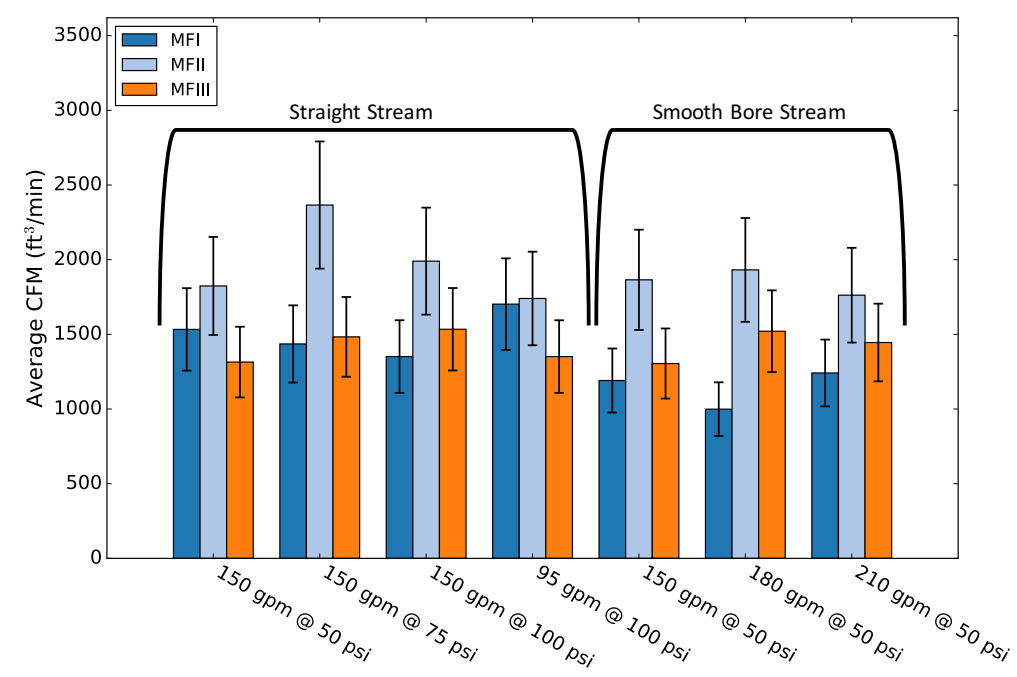

Figure 6.3: Straight stream versus smooth bore stream across manufacturers.

This also holds true when a smooth bore stream and straight stream are both being used to produce a movement pattern. For example, an ' $\mathrm{O}$ ' pattern with a smooth bore does not result in any more or less air entrainment than a straight stream. Figure 6.4 shows data for each of the $13 / 4$ in nozzles tested with an 'O' pattern. Moving the nozzle increases the air entrainment similarly for both a smooth bore and straight stream, regardless of the flow or pressure. Over the 21 different tests there is no discernible difference between manufacturers or nozzle type. 


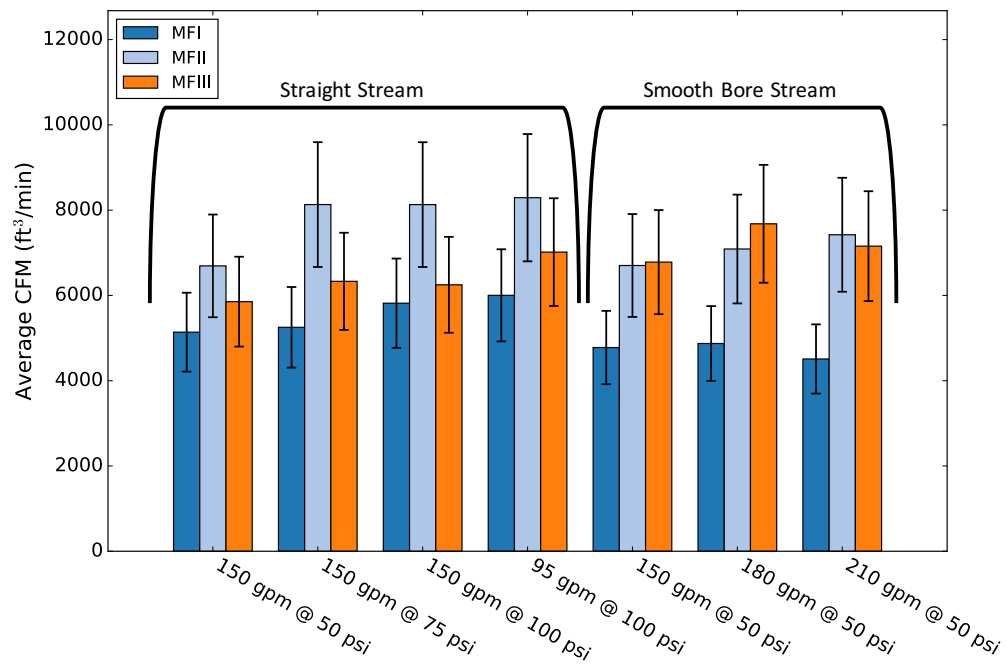

Figure 6.4: Straight stream versus smooth bore stream across manufacturers - 'O' pattern.

In the context of structural fire suppression using hand-held hose streams, both streams entrain the same amount of air when operated in the same manner.

\subsection{Increasing the Width of a Fog Pattern Increases Air En- trainment}

The amount of air moved with a fire service hose stream depends on how much the stream breaks up. The amount the stream breaks up is often thought of in terms of the stream type (smooth bore, straight stream, and fog). Understanding how the three stream types can either increase or decrease air entrainment provides the nozzle firefighter with tactical options when faced with a situation where they need to move more or less air. Recall the impact on air entrainment of changing stream type from Figures 5.1 and 5.2.

When a combination nozzle is utilized, the nozzle firefighter has additional tactical choices. As the nozzle pattern is adjusted from straight stream, to narrow fog, to wide fog, it causes the stream to break up progressively more. This leads to more entrainment as the stream goes from straight stream to wide fog. Figure 6.5 shows this for three positions: straight stream, narrow fog and wide fog, with the nozzle $3 \mathrm{ft}$ from an opening, simulating hydraulic ventilation. In the context of hydraulic ventilation, the intent is to move as much air as possible, therefore adjusting the nozzle to a wide fog results in significantly more air movement, almost double that of the narrow fog. 


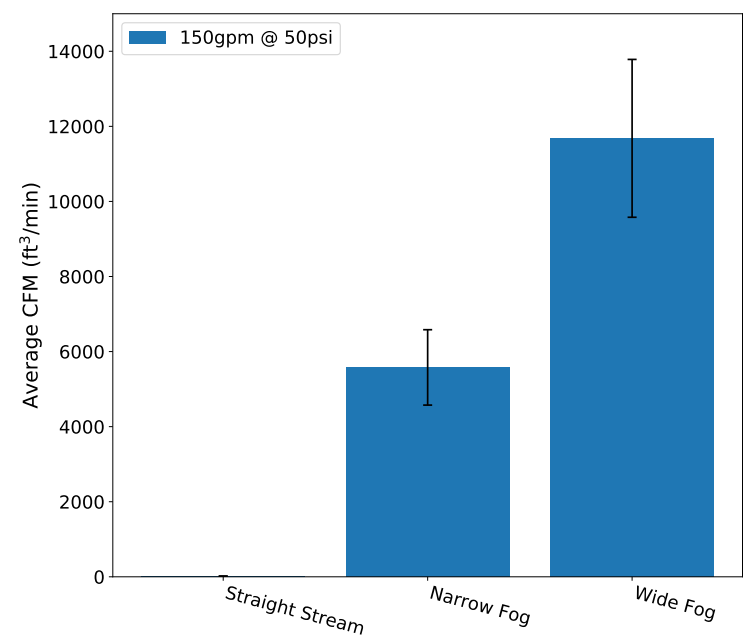

Figure 6.5: Straight stream versus narrow fog versus wide fog - $3 \mathrm{ft}$ from opening.

If the same nozzle is being used in a scenario where the nozzle firefighter is looking to limit the amount of air moved the nozzle should be placed in the straight stream pattern.

\subsection{An Increase in Stream Length Increases Air Entrainment}

Without the aid of modern personal protective equipment, early fire service nozzles needed to be designed for reach; to provide protection for firefighters by keeping distance between them and the fire. A long reach also meant a greater ability to suppress fires on upper floors without having to drag hose lines through the building. However, the longer the distance a hose stream travels before it hits a surface (stream length), the more air the stream will entrain.

\subsubsection{Stream Length and Hydraulic Ventilation}

Keeping all other factors the same, as a hose stream is moved back from a vent opening, it exhausts more and more air from the structure. Figure 6.6 shows the different values recorded at $3 \mathrm{ft}$ increments back from a double door with a narrow fog. The farther back the nozzle is from the opening, the more air is entrained in the hose stream. 


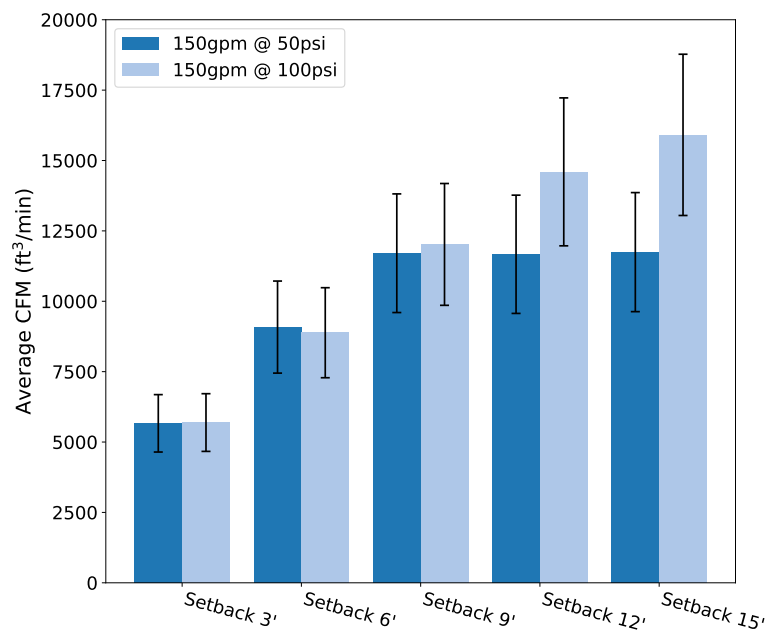

Figure 6.6: Effect of stream length on entrainment - hydraulic ventilation.

When using a nozzle for hydraulic ventilation, the intent is to provide the greatest air entrainment (exhaust). In this case, the nozzle should be located as far back in the room as possible. Increasing the length of the stream located inside the structure will in turn increase the air entrainment and thus exhaust capabilities. As Figure 6.6 shows, the exhaust capabilities of a narrow fog stream located $9 \mathrm{ft}$ back from the opening are almost double that of the case where the fog stream was $3 \mathrm{ft}$ from the opening.

\subsubsection{Stream Length and Exterior Water Application}

Stream length has the same effect on air entrainment for exterior water application, however the intent of the nozzle firefighter is much different. When applying water from the exterior into a compartment, limiting the air entrainment limits the amount the vent is blocked, maximizing the amount of combustion products that can escape. Locating the nozzle a close, but safe, distance from the opening limits the air entrainment. The farther from the opening the nozzle is located the more air is entrained.

Figure 6.7 shows the comparison of a straight stream and narrow fog $3 \mathrm{ft}$ from the opening versus $12 \mathrm{ft}$ from the opening. Although the straight stream entrains only $1 / 5$ the air the narrow fog does, the distance from the opening still had a significant impact on the amount of air entrained. 


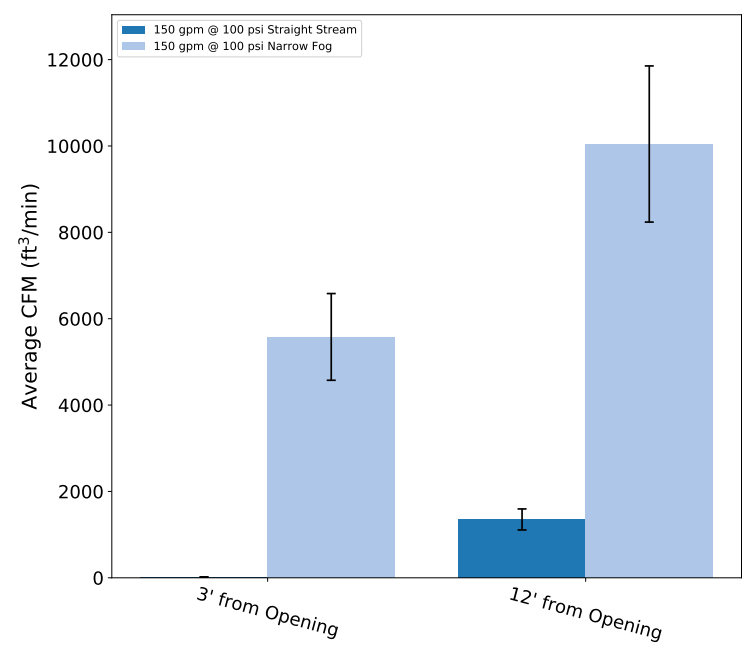

Figure 6.7: Effect of stream length on entrainment - exterior water application.

In the case of an exterior stream application on a second-floor fire, the vertical distance is fixed, however minimizing the distance from the structure limits the air entrainment. Figure 6.8 compares the two exterior attacks in. The image with the nozzle firefighter close to the structure, at the steepest angle possible, provided the least air entrainment, which in turn, maximized the exhaust of the compartment.
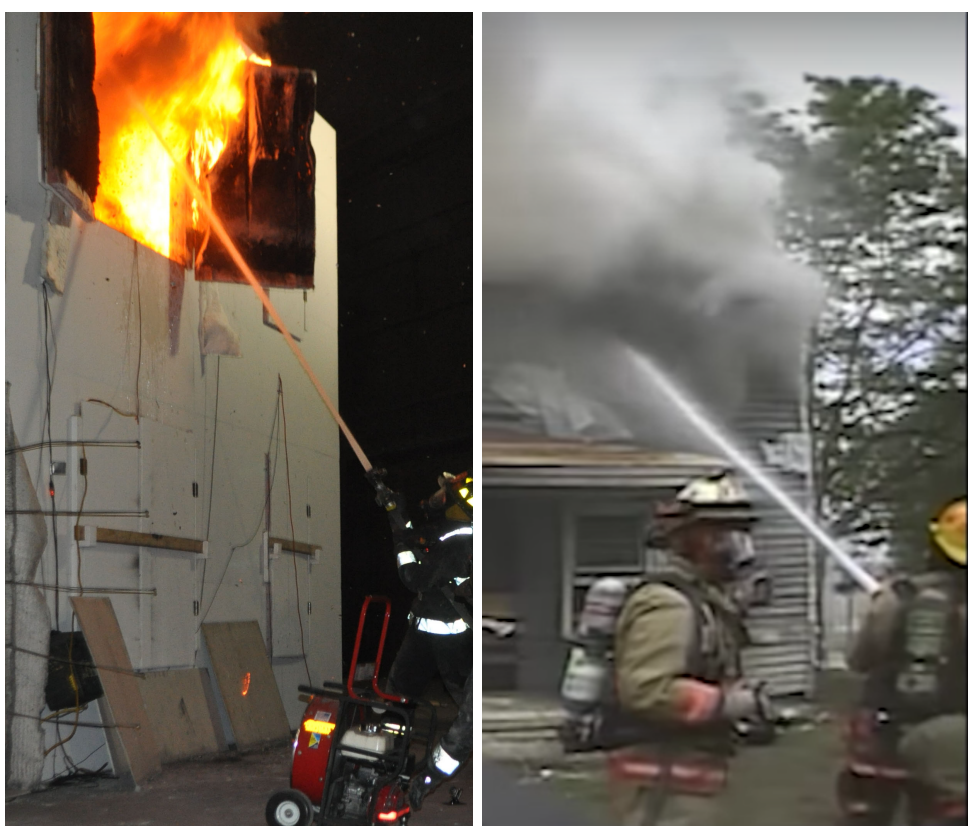

Figure 6.8: Distance from the opening has an impact on air entrainment. 


\subsection{Nozzle Movement Increases Entrainment}

Often, engine company tactics have the goal of moving air with a hose stream. In the case of a structure fire, the intent is often to move products of combustion or 'smoke'. An understanding of how different nozzle movement can entrain more air or less air can aid in accomplishing the intended tactic.

The amount of air or 'smoke' moved by the nozzle is related to the speed the nozzle is moved. Moving the nozzle causes the stream to break up. As the nozzle is moved faster, more droplets are created and more air is entrained. This was demonstrated in Figure 5.7, where the number of revolutions in an ' $\mathrm{O}$ ' pattern is increased from 50/min to $100 / \mathrm{min}$ and finally $150 / \mathrm{min}$. As the speed of movement increased, the amount of air moved increased. A firefighter trying to move air or smoke should increase the movement of the nozzle. Inversely, a firefighter trying to move as little air as possible should hold the nozzle as still as possible.

When the intent is to move air, the pattern chosen has little effect on the entrainment. Using a 'O', 'Z', 'n' or just moving the nozzle rapidly ('Spray and Pray') all were found to have similar air entrainment. Figure 5.5 showed air entrainment of approximately 5000 CFM for all the nozzle patterns tested with a $13 / 4$ in hoseline regardless of pattern or nozzle type. Figure 5.6 showed an 'O' pattern compared to a 'Spray and Pray' pattern.

\subsection{Comparing Entrainment to PPV Fan Exhaust}

When the intent is to move the most air, a fog stream in an 'O' pattern was seen to produce the most airflow. At $10 \mathrm{ft}$ back from the opening values in excess of 15000 CFM were recorded. For comparison (Figure 6.9), a PPV fan was found to flow approximately 8000 CFM on a 1:1 exhaust to inlet ratio in a single-story structure. When the exhaust to inlet ratio was 2:1 the same fan was flowing approximately $15000 \mathrm{CFM}$ [13]. If the intent is to provide hydraulic ventilation, a narrow fog moved in an ' $\mathrm{O}$ ' pattern, as far back from the opening as possible, will entrain a comparable amount of air as positive pressure ventilation. 


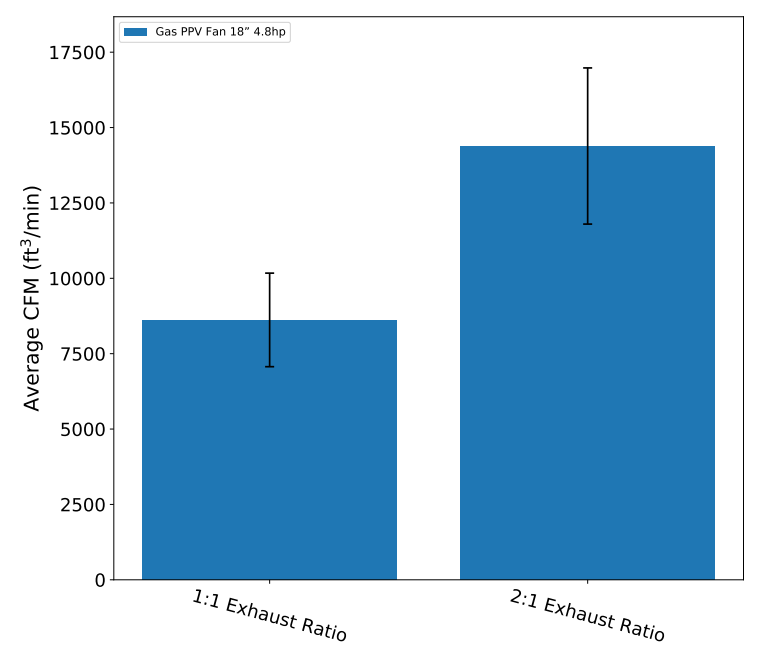

Figure 6.9: Single story structure exhaust - PPV [13].

\subsection{What Did Not Affect Air Entrainment}

Tactical choices such as nozzle pressure, nozzle flow rate and hose size (1 3/4 in vs. 2 1/2 in) are often thought to have additional implications other than increased flow. This did not hold true for air entrainment. Choosing a larger hose line, higher nozzle pressure or larger flow rate did not provide significant differences in the amount of air entrained (Section 5.3). Although these choices do impact the pressure loss in the hose, nozzle reaction, manpower needed, and total water flow, they did not impact air entrainment in these experiments. 


\section{Future Research Needs}

The air entrainment data presented in this report is one piece of the fire attack study. The intention of this report is to provide results and insight into the amount of air entrained by hose streams based on pre-determined variables and parameters. Water distribution data and full-scale fire test data are additional components to the study which are needed to create a holistic understanding. Upon completion of the entire analysis, conclusions can be drawn, and tactical considerations can be developed regarding each experimental series, the relationships between the series, and the project in its entirety. 


\section{Summary}

This series of experiments looked to quantify air entrainment by hand-held fire hose streams, expanding on work already done looking at hydraulic ventilation [6-9]. The results show that to increase entrainment, a firefighter should create a more broken stream or fog pattern, move the nozzle rapidly and provide the largest stream length. If the intent is to limit air entrainment, the nozzle firefighter should use a fixed nozzle position on a smooth bore or straight stream and limit the stream length where possible. No difference was seen between air entrainment in a smooth bore stream versus a straight stream. Understanding these key concepts of air entrainment can aid firefighters in being more effective. Applying these concepts to structural firefighting allows for better control of air entrainment during both interior and exterior operations. 


\section{References}

[1] S. Kerber. Impact of Ventilation on Fire Behavior in Legacy and Contemporary Residential Construction. Report, Underwriters Laboratories, 2014.

[2] S. Kerber. Study of the effectiveness of fire service vertical ventilation and suppression tactics in single family homes. Report, Underwriters Laboratories, 2013.

[3] S. Kerber and R. Zevotek. Study of residential attic fire mitigation tactics and exterior fire spread hazards on firefighter safety. Report, Underwriters Laboratories, 2014.

[4] F. M. Stowell and L. Murnane, editors. Essential of Firefighting and Fire Department Operations. Brady Publishing, International Fire Service Training Association, 6 edition.

[5] Glenn Corbett, editor. Fire Engineering's Handbook for Firefighter I and II. PennWell Corporation.

[6] J. Knapp, T. Pillsworth, and S. White. Nozzle Tests Prove Fireground Realities, Part 1. Fire Engineering, February 2003.

[7] J. Knapp, T. Pillsworth, and S. White. Nozzle Tests Prove Fireground Realities, Part 2. Fire Engineering, September 2003.

[8] J. Knapp, T. Pillsworth, and S. White. Nozzle Tests Prove Fireground Realities, Part 3. Fire Engineering, September 2003.

[9] J. Willi, C. Weinschenk, and D. Madrzykowski. Impact of hose streams on air flows inside a structure. Nist technical report 1938, National Institutes of Standards and Technology, Gaithersburg, MD, 2016.

[10] R.A. Bryant. A comparison of gas velocity measurements in a full-scale enclosure fire. Fire Safety Journal, 44:793-800, 2009.

[11] Blower Door Operation Manual. Everson, WA, March 2015.

[12] B.J. Klaene and R.E. Sanders. Structural Fire Fighting. National Fire Protection Association, Quincy, MA, 2000.

[13] R Zevotek and S. Kerber. Study of the effectiveness of fire service positive pressure ventilation during fire attack in single family homes incorporating modern construction practices. Technical report, UL Firefighter Safety Research Institute, Columbia, MD, 2016. 


\section{Appendix A Air Entrainment Figures}
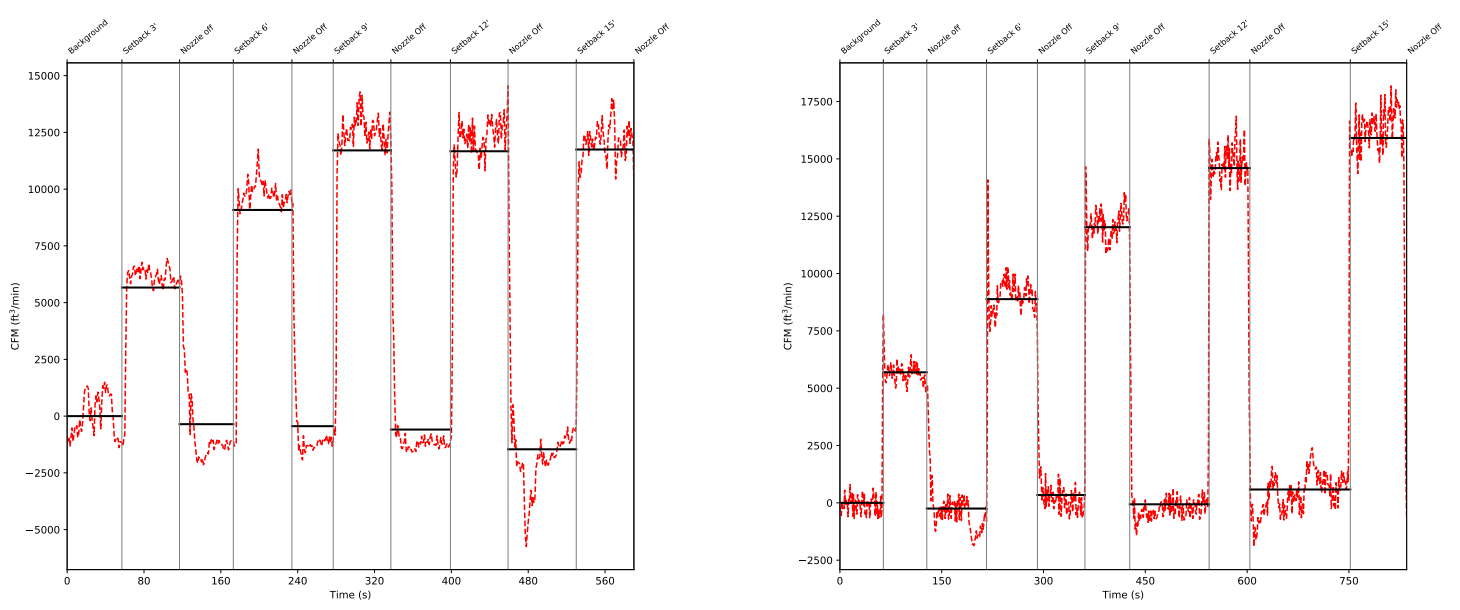

Figure A.1: Air entrainment results for varying distances from the ventilation opening using a combination nozzle on a $13 / 4$ in hoseline: 150 gpm @ 50 psi (left) and 150 gpm @ 100 psi (right).

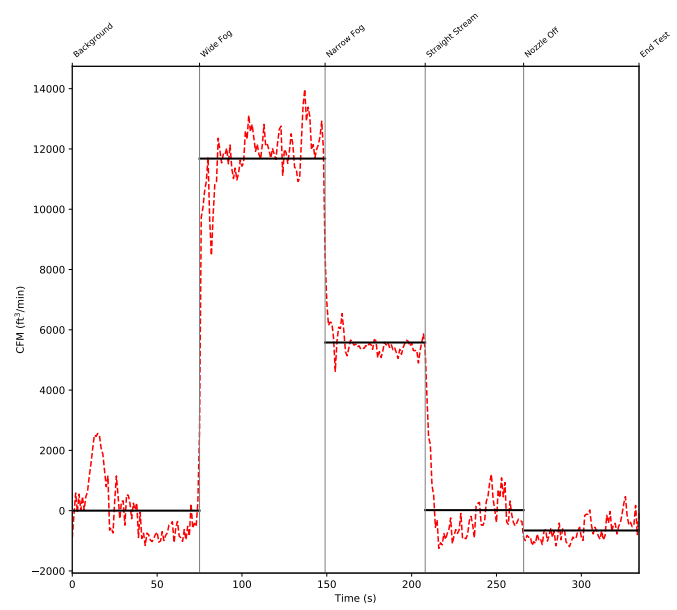

Figure A.2: Air entrainment results for ventilation opening occlusion utilizing a combination nozzle on a $13 / 4$ in hoseline: 150 gpm @ 100 psi. 

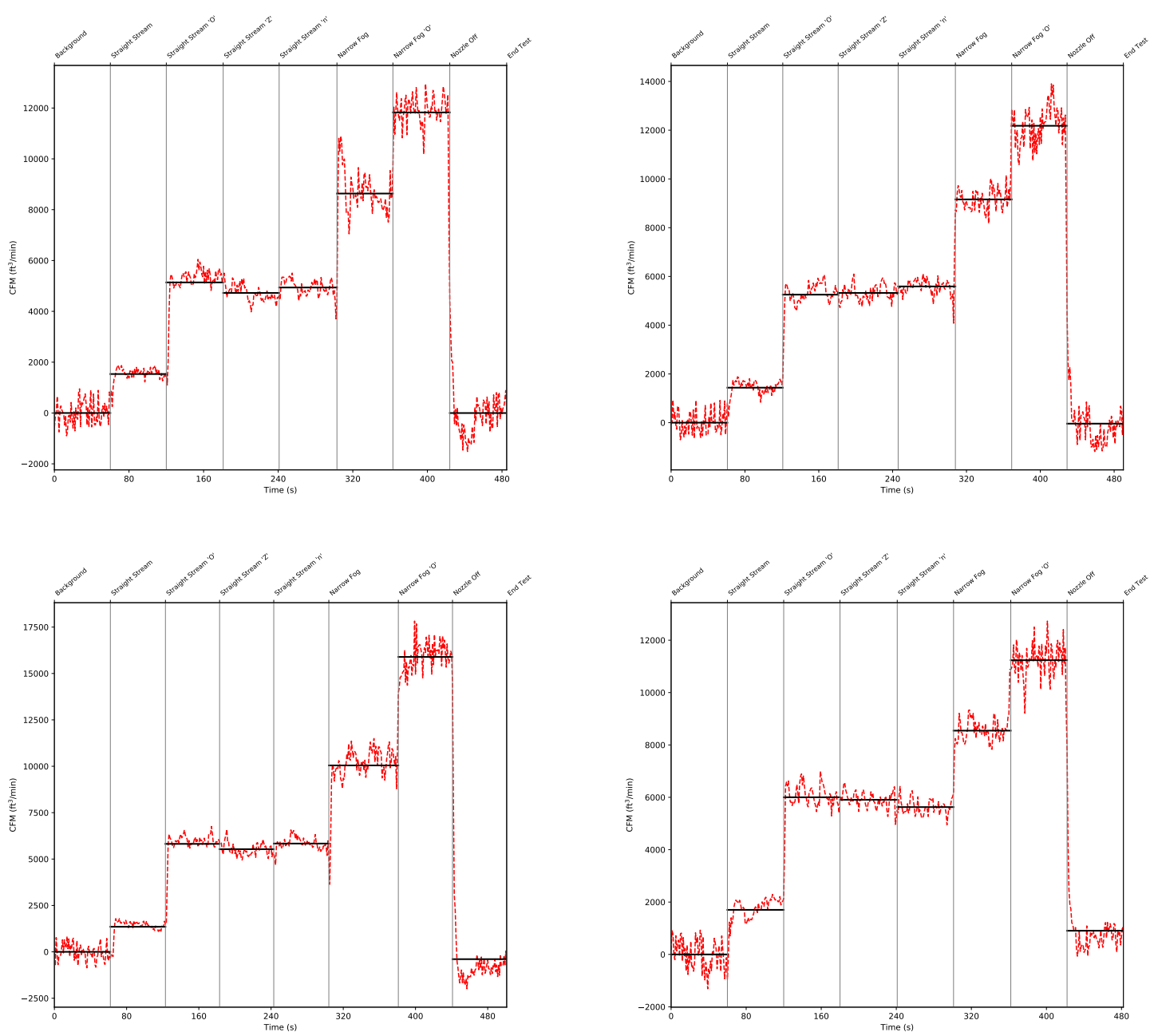

Figure A.3: Manufacturer I comparison of interior air entrainment results for combination nozzles on a $13 / 4$ in hoseline: 150 gpm @ 50 psi (top left), 150 gpm @ 75 psi (top right), 150 gpm @ 100 psi (bottom left), and 95 gpm @ 100 psi (bottom right). 

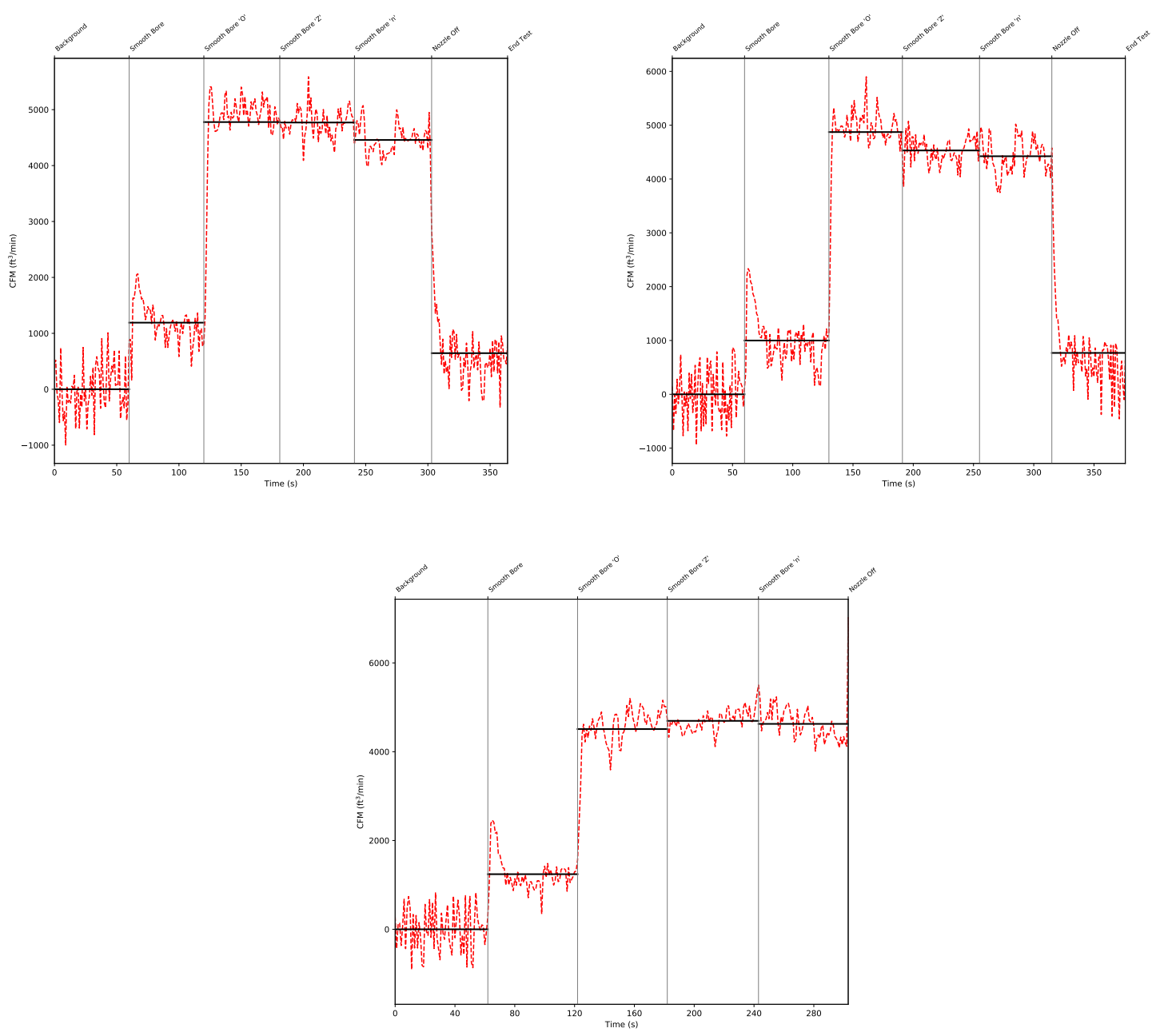

Figure A.4: Manufacturer I comparison of interior air entrainment results for smooth bore nozzles on a $13 / 4$ in hoseline: 7/8 in tip flowing $150 \mathrm{gpm} @ 50 \mathrm{psi}$ (top left), 15/16 in tip flowing 180 gpm @ 50 psi (top right), and 1 in tip flowing 210 gpm @ 50 psi (bottom). 

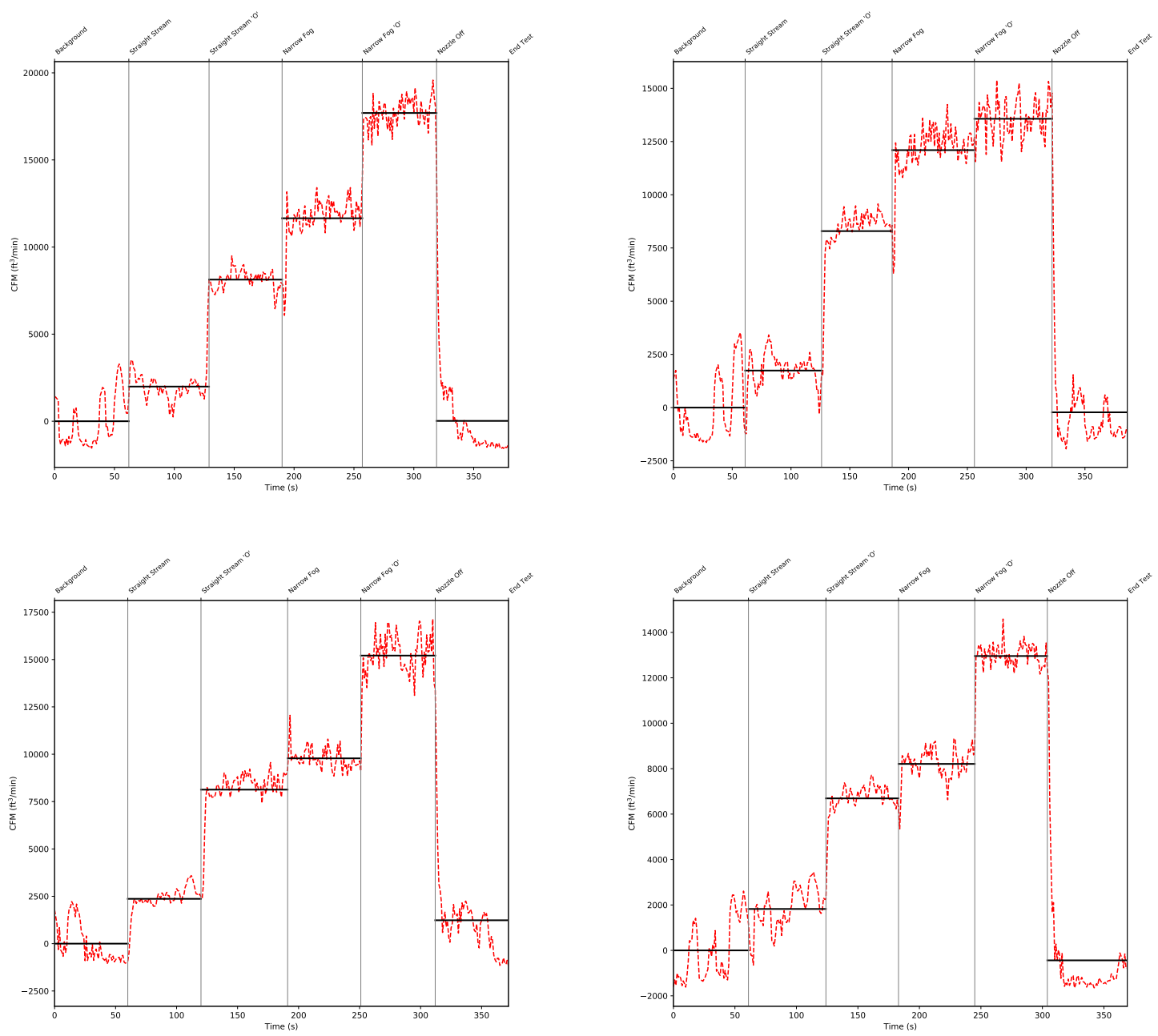

Figure A.5: Manufacturer II comparison of interior air entrainment results for combination nozzles on a $13 / 4$ in hoseline: 150 gpm @ 100 psi (top left), 95 gpm @ 100 psi (top right), 150 gpm @ 75 psi (bottom left), and 150 gpm @ 50 psi (bottom right). 

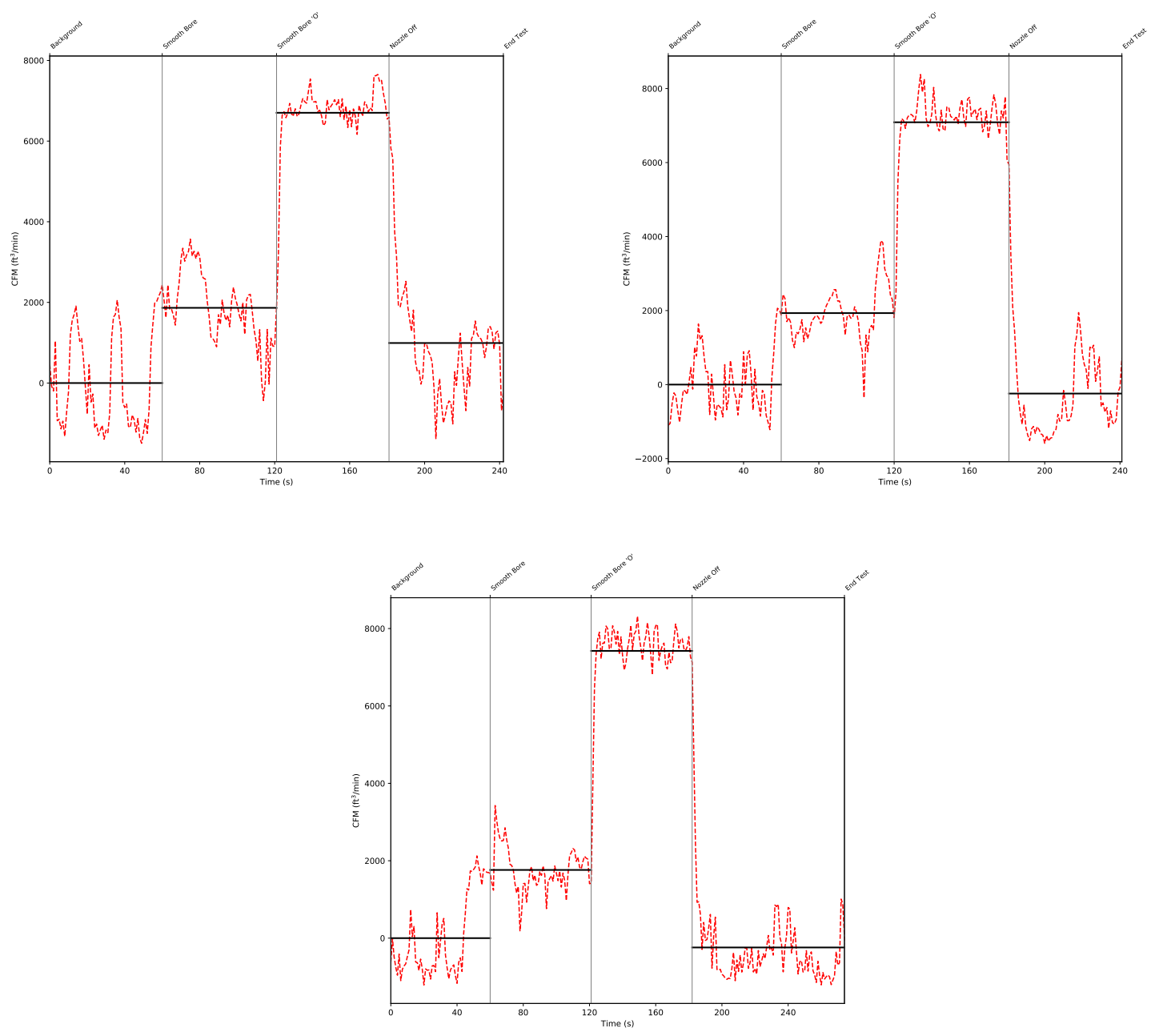

Figure A.6: Manufacturer II comparison of interior air entrainment results for smooth bore nozzles on a $13 / 4$ in hoseline: 7/8 in tip flowing $150 \mathrm{gpm} @ 50 \mathrm{psi}$ (top left), 15/16 in tip flowing 180 gpm @ 50 psi (top right), and 1 in tip flowing 210 gpm @ 50 psi (bottom). 

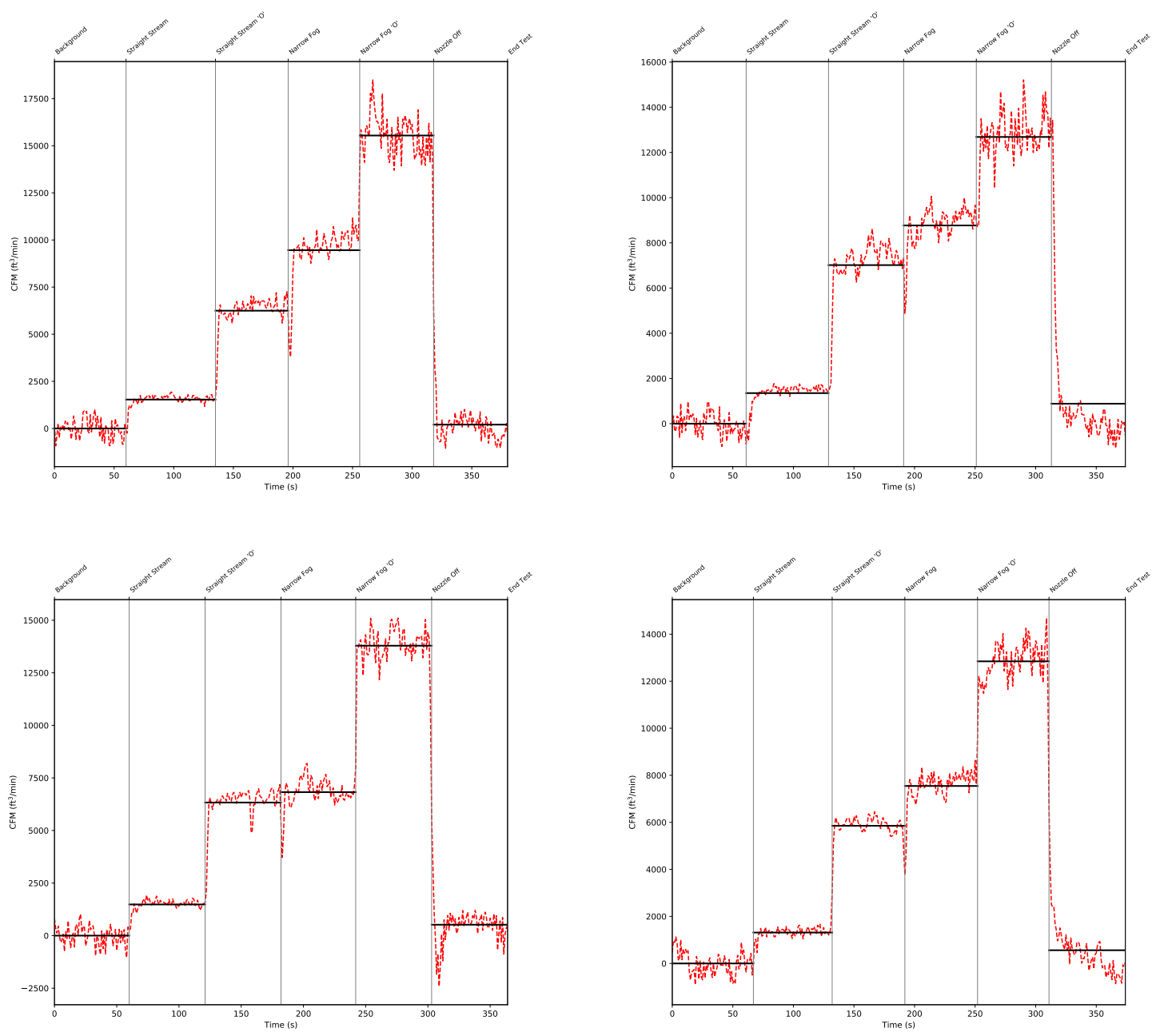

Figure A.7: Manufacturer III comparison of interior air entrainment results for combination nozzles on a $13 / 4$ in hoseline: 150 gpm @ 100 psi (top left), 95 gpm @ 100 psi (top right), 150 gpm @ 75 psi (bottom left), and 150 gpm @ 100 psi (bottom right). 

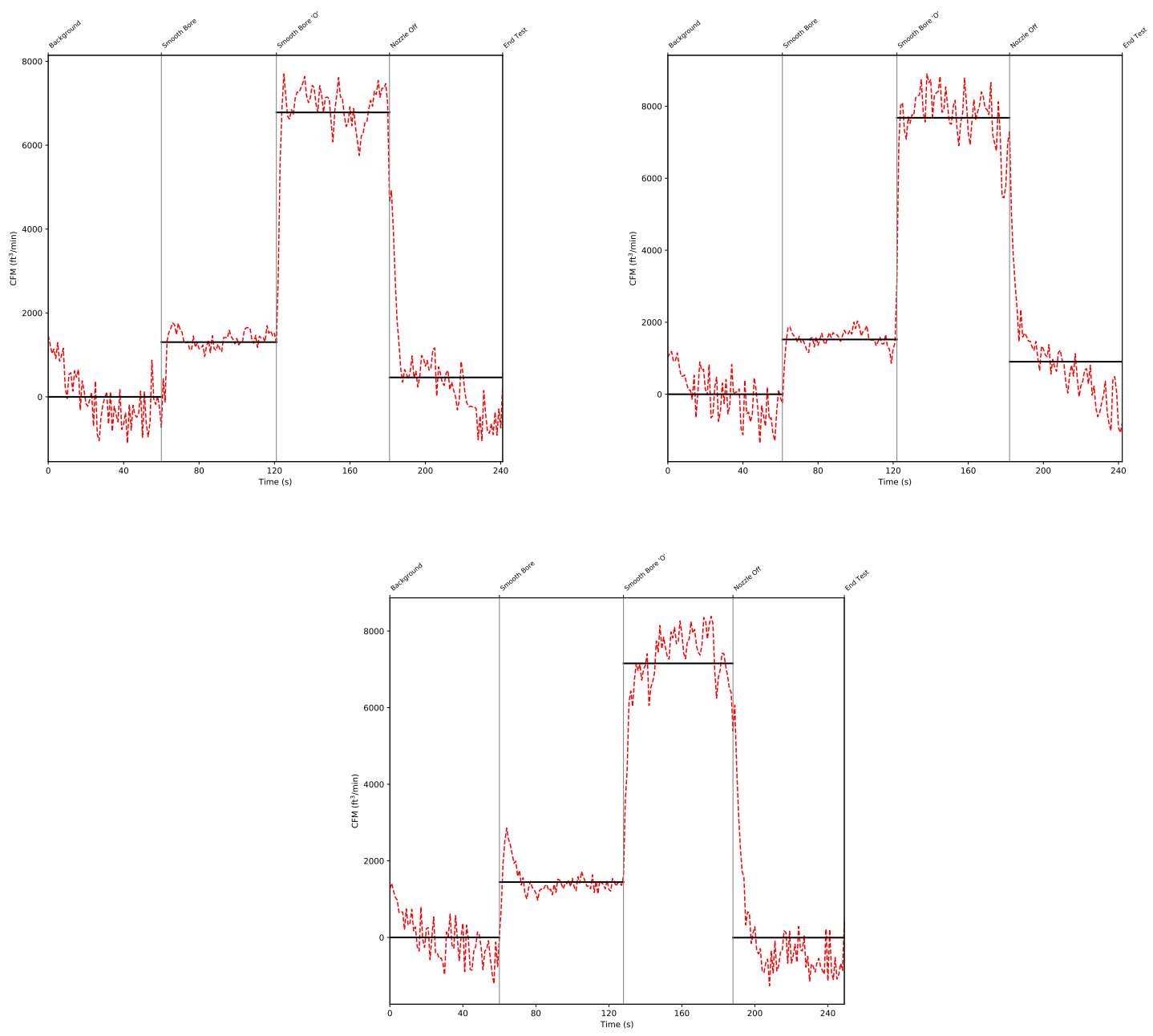

Figure A.8: Manufacturer III comparison of interior air entrainment results for smooth bore nozzles on a $13 / 4$ in hoseline: 7/8 in tip flowing $150 \mathrm{gpm} @ 50 \mathrm{psi}$ (top left), 15/16 in tip flowing 180 gpm @ 50 psi (top right), and 1 in tip flowing 210 gpm @ 50 psi (bottom). 

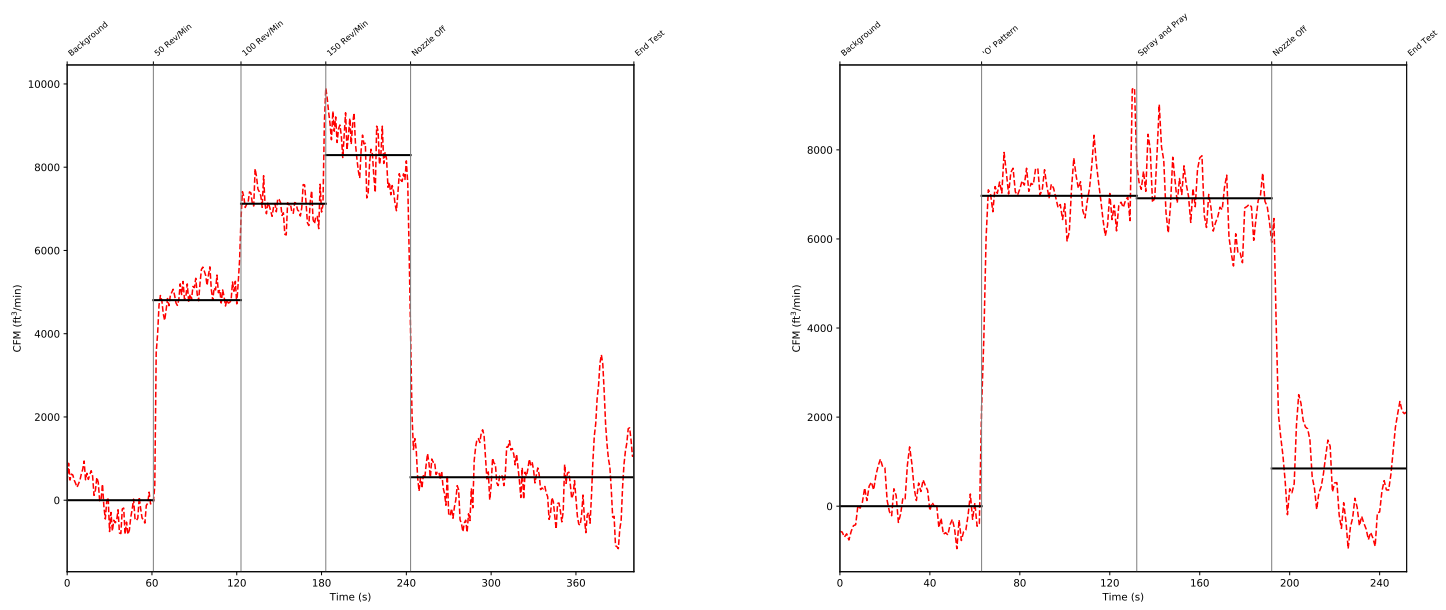

Figure A.9: Air entrainment results for a smooth bore nozzle utilizing a 1 in tip flowing 210 gpm @ 50 psi on a $13 / 4$ in hoseline: 'O' Pattern (left) and Spray and Pray (right). 

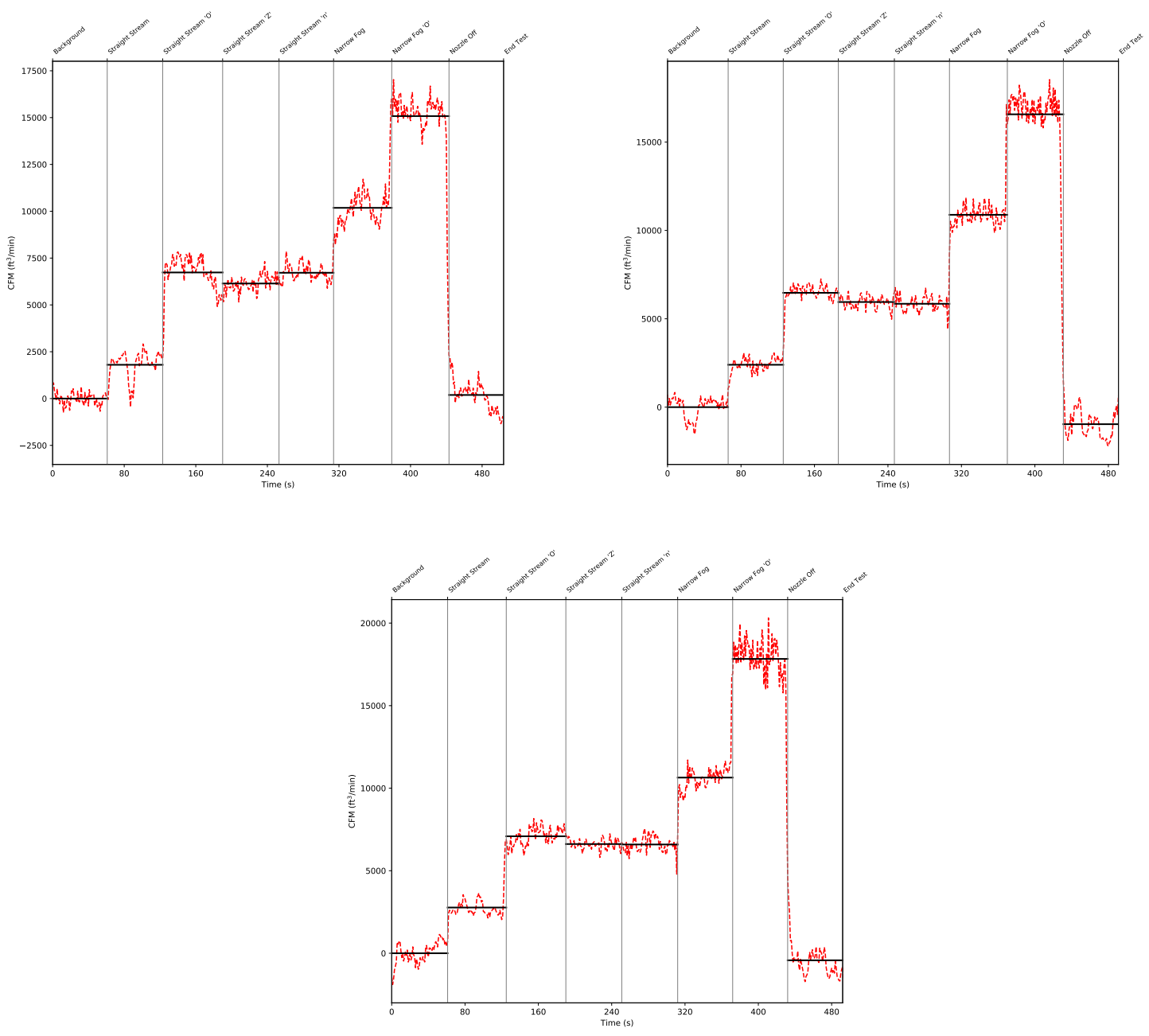

Figure A.10: Interior air entrainment results for combination nozzles on a $21 / 2$ in hoseline: 250 gpm @ 50 psi (top left), 250 gpm @ 75 psi (top right), 250 gpm @ 100 psi (bottom). 

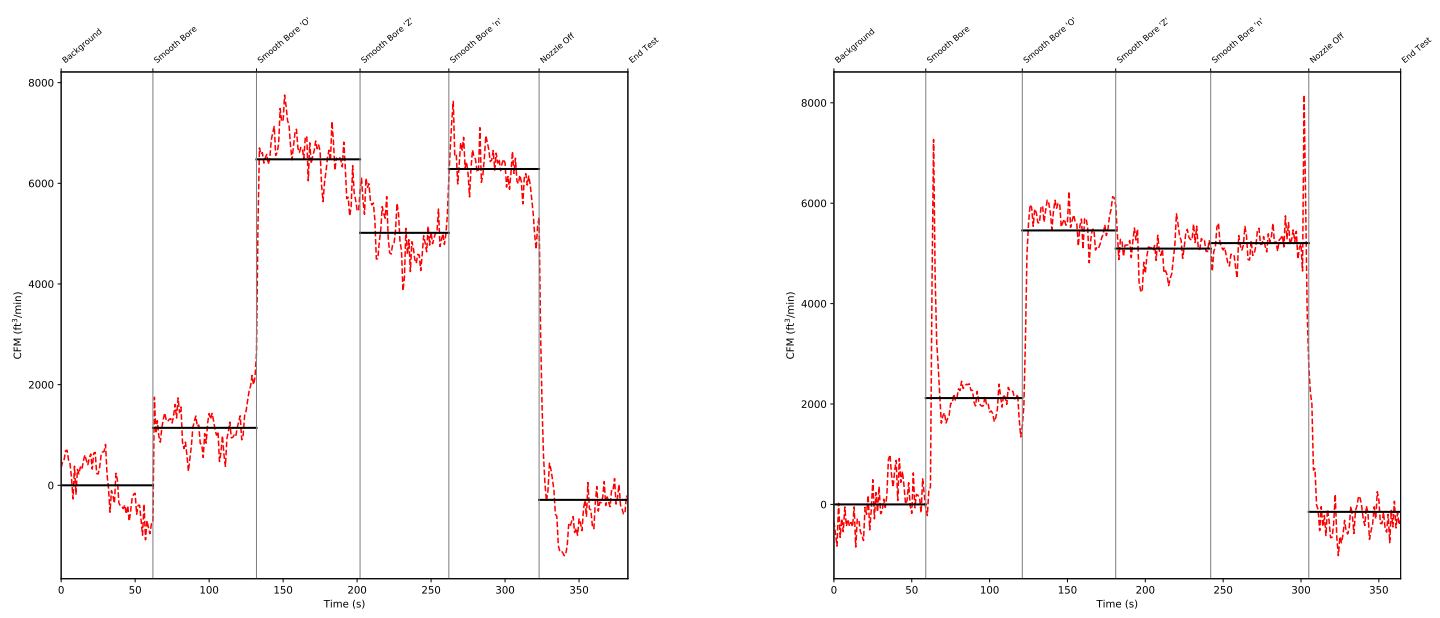

Figure A.11: Interior air entrainment results for smooth bore nozzles on a $21 / 2$ in hoseline: 1 1/8 in tip flowing 260 gpm @ 50 psi (left) and 1 1/4 in tip flowing 320 gpm @ 50 psi (right). 

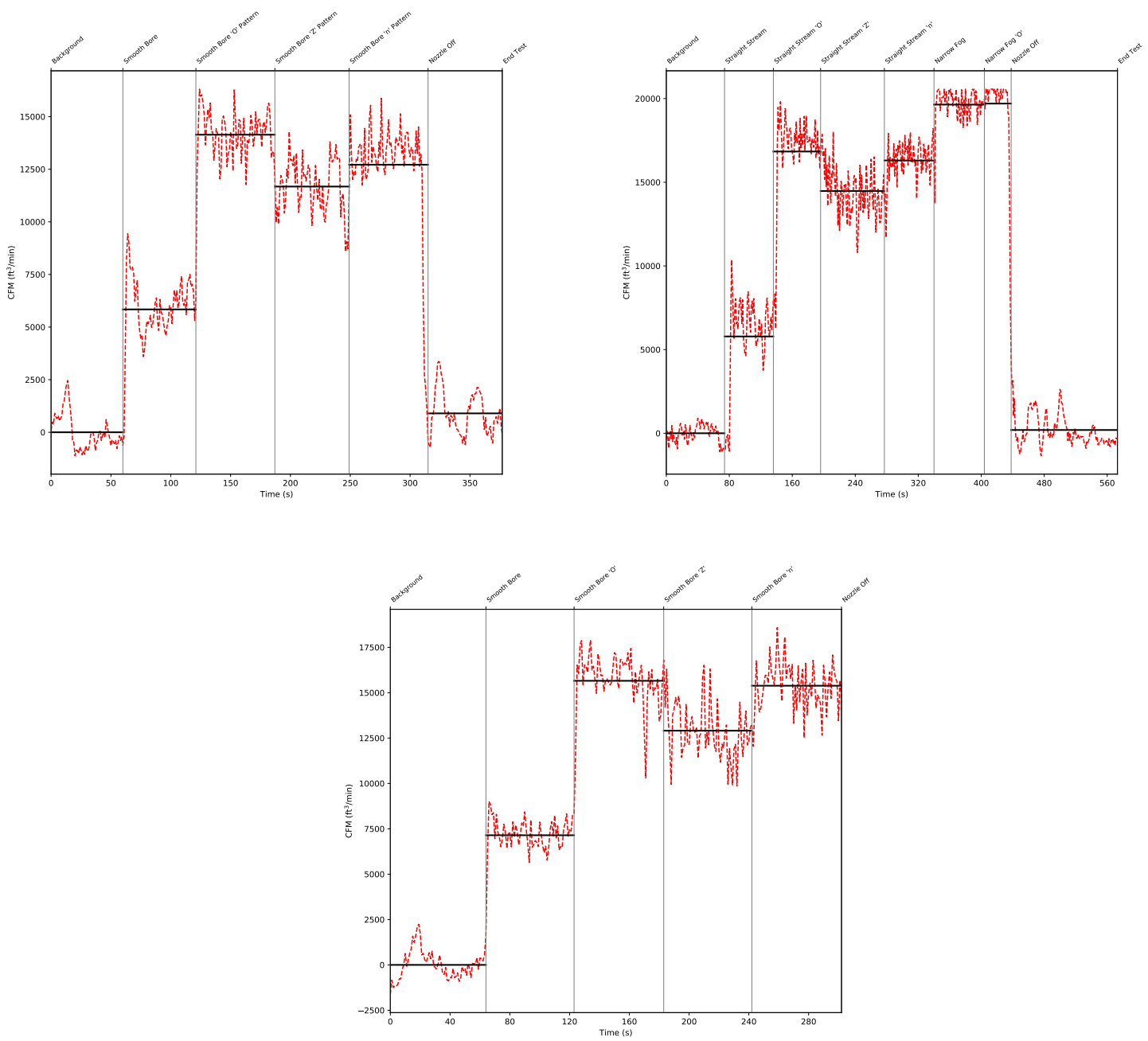

Figure A.12: Exterior air entrainment results: smooth bore nozzle with a 15/16 in tip on a $13 / 4$ in hoseline flowing $180 \mathrm{gpm} @ 50 \mathrm{psi}$ (top left), combination nozzle on a $21 / 2$ in hoseline flowing 250 gpm @ 75 psi (top right), and a smooth bore nozzle with a $11 / 4$ in tip on a $21 / 2$ in hoseline flowing 320 gpm @ 50 psi (bottom). 

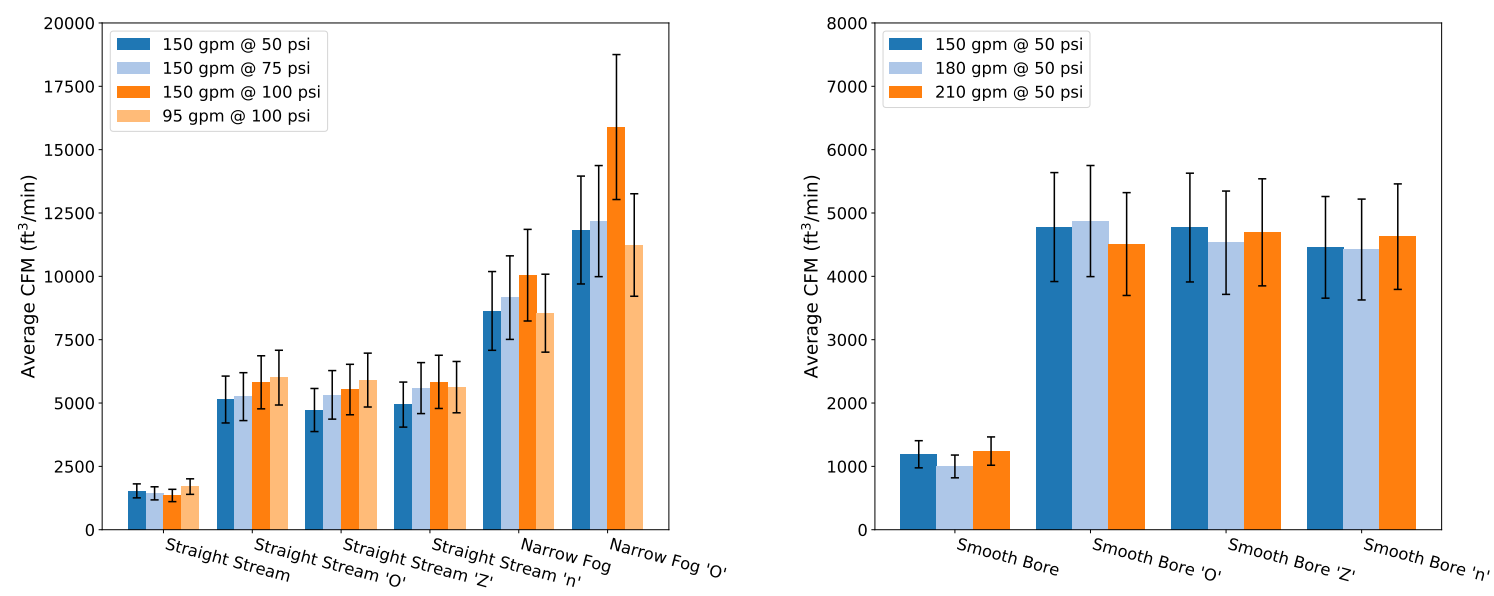

Figure A.13: Interior air entrainment results for both combination and smooth bore nozzles on a 1 3/4 in hoseline showing all nozzle patterns: Combination Nozzle (left) and Smooth Bore Nozzle (right). 


\section{Appendix B Known Source Experiments}
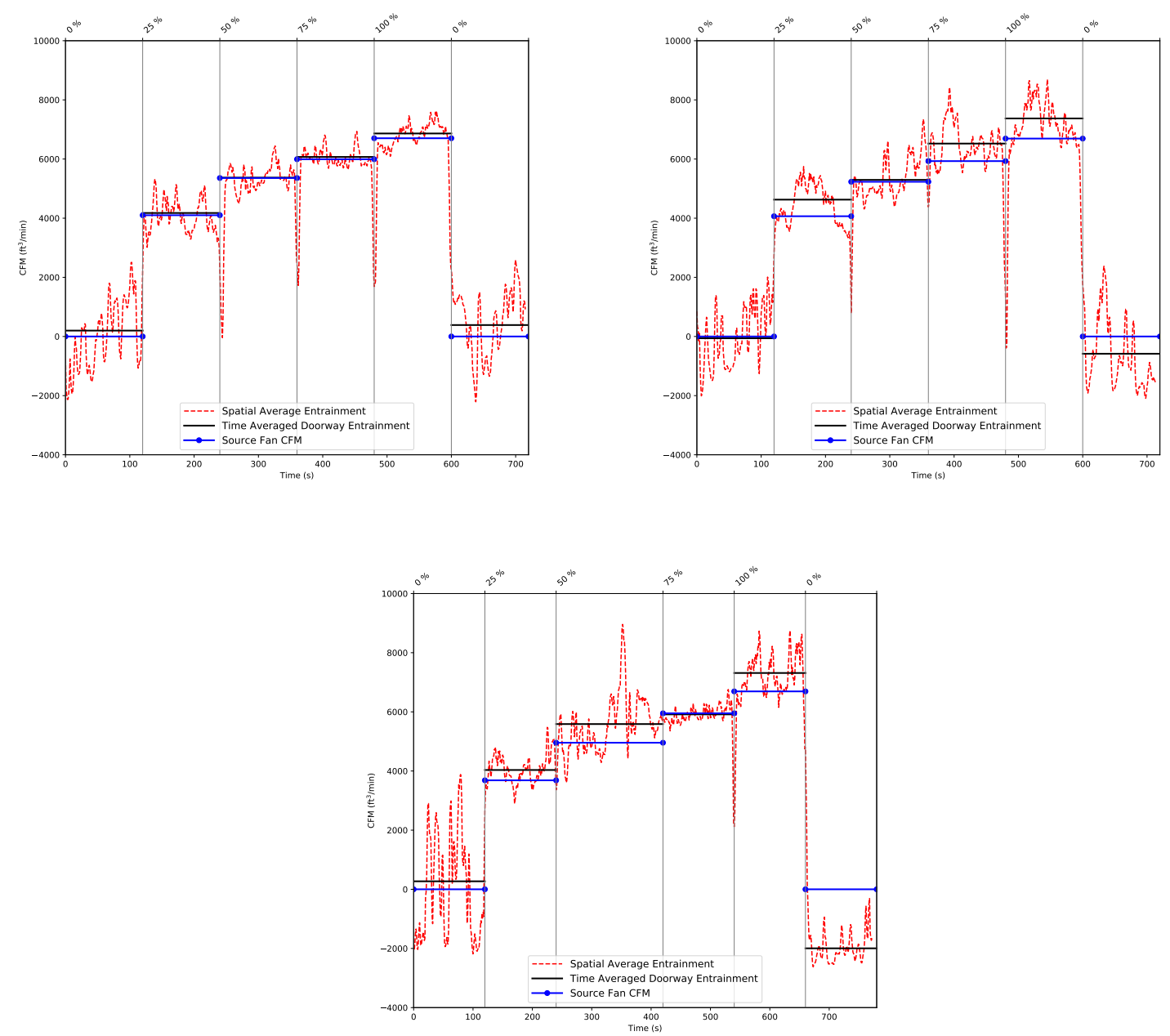

Figure B.1: Replicate experiments to compare measured air entrainment values to a blower door (known source) with a single door exhaust. 

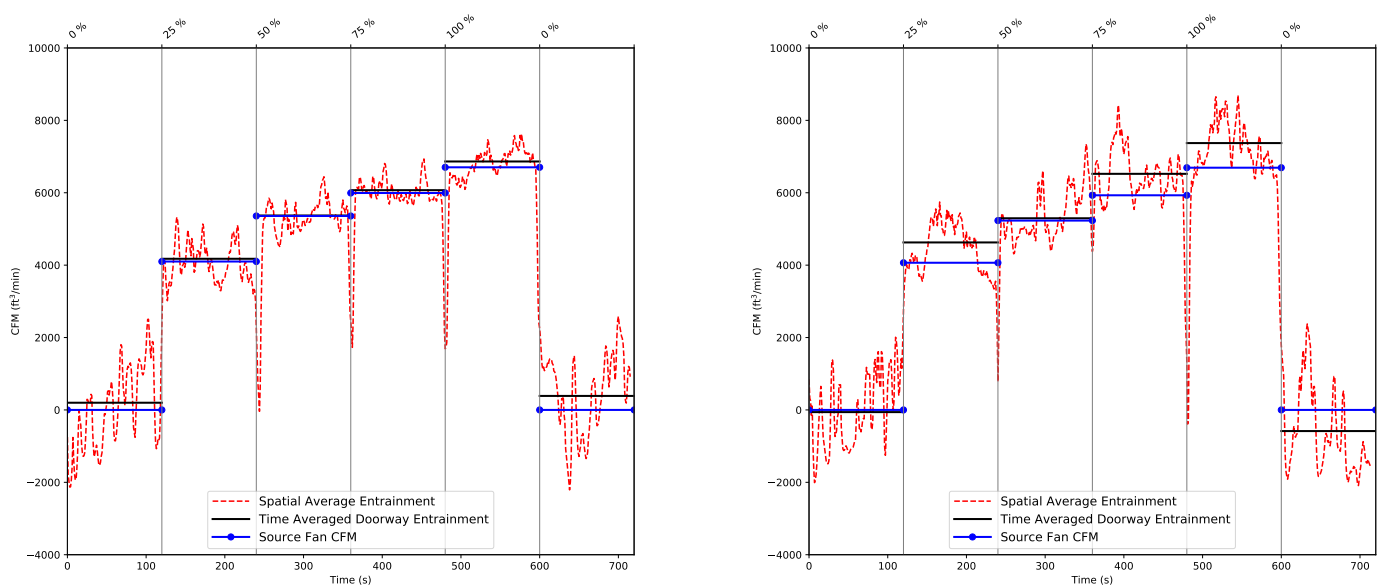

Figure B.2: Replicate experiments to compare measured air entrainment values to a blower door (known source) with a double door exhaust. 